\title{
LAS CUENTAS DE COLLAR EN VARISCITA DE LAS MINAS PREHISTÓRICAS DE GAVÀ (CAN TINTORER). BASES PARA UN ESTUDIO EXPERIMENTAL
}

\author{
María José NoAin MaURA \\ Universidad Autónoma de Madrid
}

\section{Resumen}

En la provincia de Barcelona se encuentra el yacimiento de las Minas Prehistóricas de Gavà (Can Tintorer), una explotación minera que comenzó en el Neolítico antiguo postcardial y tuvo su máximo apogeo durante el Neolítico medio, dentro de la Cultura Catalana de los Sepulcros de Fosa. En las minas se extraía la variscita o calaíta, piedra de color verde destinada a la fabricación de cuentas de collar. En este trabajo, hemos estudiado dichas cuentas en proceso de fabricación y a partir de los materiales arqueológicos, hemos reproducido experimentalmente el proceso de fabricación (fragmentación de la variscita, pulimento y perforación de la cuenta), comparando después los resultados obtenidos con los datos extraídos del estudio de las cuentas arqueológicas, haciendo especial hincapié en las huellas de fabricación, observadas a través de lupa binocular.

\begin{abstract}
The site of the Prehistoric Mines of Gavà (Can Tintorer), located in the province of Barcelona (Spain), is a mining explotation that started in the Early Neolithic postcardial period and peaked during the Middle Neolithic, within the Catalan Culture of Grave Tombs. The extraction of the mines produced variscita/calaita, a green colored stone used for the manufacture of necklace beads. In this paper, we have studied the beads during the manufacturing process and, using as a starting point the archaeological material, we have reproduced experimentally this process (fragmentation of the variscita, polishing and drilling of the bead), comparing the results with the data obtained from the study of the archaeological beads themselves, in particular manufacturing traces, as observed through a binocular magnifying lense.
\end{abstract}

\section{LAS MINAS PREHISTÓRICAS DE GAVÀ (CAN TINTORER)}

Las minas de Can Tintorer se encuentran en el municipio de Gavà, en la provincia de Barcelona, a $20 \mathrm{~km}$. de la capital. Se localizan en el borde suroriental de la cordillera litoral, en el margen derecho del río Llobregat (figura 1). 

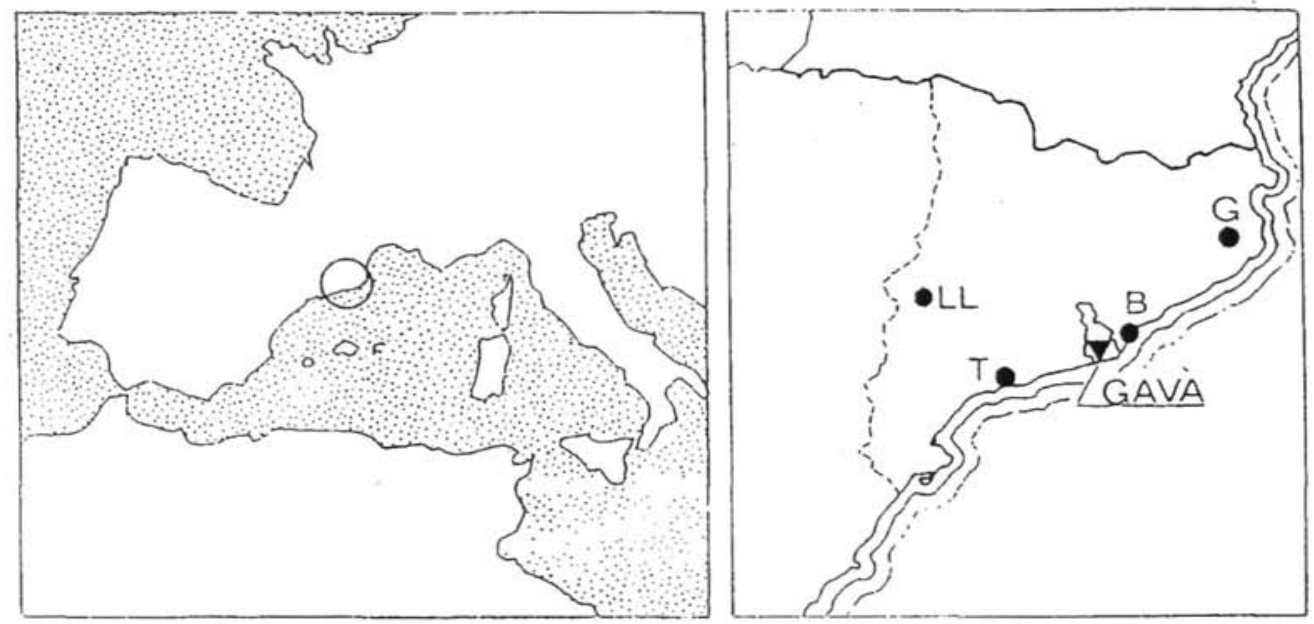

Figura 1. Mapa de situación de las Minas Prehistóricas de Gavà (a partir de Rubricatum, $\mathrm{n}^{2} 0$, pág. 25)

Deben su nombre original al barrio en el que se descubrieron y hoy en día son más conocidas como las Minas Prehistóricas de Gavà debido a que han rebasado el ámbito de Can Tintorer.

Actualmente, el yacimiento abarca unas 250 hectáreas.

El yacimiento corresponde a una explotación minera, que comenzó durante el Neolítico antiguo postcardial y se prolongó durante todo el Neolítico Medio, siendo ésta su época de máxima explotación, correspondiéndose a la Cultura Catalana de los Sepulcros de Fosa.

Dentro de los ajuares que caracterizan este periodo, uno de los fósiles guía que los constituyen son las cuentas de collar en variscita ${ }^{1}$, piedra de color verde destinada a la fabricación de cuentas de collar, a cuya extracción se dedicó el complejo minero. En un primer momento el equipo de investigación del Museo de Gavà supuso una explotación de diferentes materias primas, ya que costaba creer que las Minas hubieran sido construidas exclusivamente para extraer un único mineral dedicado a la fabricación de objetos ornamentales. Las Minas de este modo habrían comenzado a ser explotadas sobre todo para la extracción

'La denominación de este mineral verde siempre ha suscitado polémica. En un principio se pecó de agrupar diversas materias primas bajo un nombre común, el de calaíta, sin saber exactamente de qué mineral se trataba. Hoy en dia. tampoco somos exactos cuando denominamos "variscita" a piedras verdes que todavia no han sido sometidas a un análisis que confirme su composición. Además los mineros de Gavà no distinguían entre los diferentes minerales. sino que simplemente explotaban los materiales de color verde, independientemente de su composición. En este sentido estamos de acuerdo con lo propuesto por Edo, VillalBa Y Blasco (1995), es decir, volver al término genérico de calaíta. No obstante, vamos a seguir utilizando la nomenclatura de "variscita", por ser hoy en día la comúnmente aceptada en las publicaciones y la utilizada generalmente a la hora de referirse a este material. Sólo mantendremos el nombre de "calaíta" cuando hagamos referencia a obras en los que los autores utilizan expresamente este término. 
de liditas (un tipo de ópalo), sílex y ocres. Hoy en día, los estudios geológicos parecen indicar que el auténtico móvil de desarrollo de las Minas, aunque en algún momento se explotaran otros materiales, fue la variscita y demás piedras verdes.

El conjunto minero está formado por más de 70 galerías. Las postcardiales tienen una organización geométrica lineal, con una orientación aproximada Este-Oeste y su estructura es más sencilla que las de las minas del Neolítico Medio. Las galerías suelen medir entre 5 y 15 metros de longitud, pero las hay que alcanzan los 80 metros de recorrido. La máxima profundidad detectada es de 14 metros. Su calidad varía mucho, desde un acabado muy esmerado hasta un basto alisado de las paredes. Suelen ser de sección circular, con unas dimensiones de entre 80 y $100 \mathrm{~cm}$. Como ya se ha dicho, las más antiguas son más cortas y simples en su construcción. En el Neolítico Medio pasan a ser más complejas y abundantes.

Las Minas de Gavà fueron descubiertas casualmente en 1972, cuando se abrieron una serie de zanjas destinadas a los cimientos de unos nuevos bloques de viviendas, que sacaron a la luz diversas galerías. En 1974, fueron halladas nuevas galerías con restos de enterramientos y ajuares, material que fue destruido. Con la construcción de un aparcamiento en la zona, quedaron descubiertas varias bocas de acceso a galerías. Tras estos hallazgos los vecinos de la Masía de Can Tintorer comunicaron que su bodega, presuntamente una cueva natural, presentaba características muy similares, pasando a ser catalogada como una cámara en la que confluían varias galerías.

Comenzaron a ser excavadas en el año 1978 por un grupo de arqueólogos formado por Edo, Gordo, Millán y Villalba. Este equipo publicó un primer artículo en 1977 (Alonso et alii, 1977-78) y una memoria en 1986, Les mines neolítiques de Can Tintorer, que recogía las campanas realizadas entre 1978 y 1980. Con prólogo de Maluquer de Motes, la obra, que resumía los primeros resultados, ampliaba enormemente el panorama de la investigación, aportando nuevas posibilidades de estudio y aclarando algunas de las incógnitas que rodeaban a la Cultura de los Sepulcros de Fosa.

Las excavaciones en las minas continúan hasta hoy en día, compartidas actualmente su dirección por el primer equipo y el equipo del Museo de Gavà encabezado por Josep Bosch Argilagos y Alicia Estrada (cada uno de ellos trabaja en áreas distintas del yacimiento). Este segundo equipo puso en marcha en 1991 un proyecto interdisciplinar de conservación, estudio y difusión del yacimiento, incluyendo campanas de excavación ("Proyecto de Investigación Minas Prehistóricas"). Los objetivos del proyecto eran cuatro: investigar el paleoambiente del yacimiento y su entorno; determinar la cronología de la ocupación y explotación; profundizar en las sociedades neolíticas y cambio cultural; y avanzar en el conocimiento del Neolítico en general. El proyecto incluye un estudio del esquema potencial de actividades económicas del yacimiento, a través de un Site Catchment Analysis.

Las investigaciones avanzan con cada campana, a veces con hallazgos tan espectaculares como el de la llamada Venus de Gavà. El segundo equipo mencionado publica en 1994 otra monografía sobre las últimas campañas, en el número 0 de la revista Rubricatum, dedicado al periodo del Neolítico postcardial, que se confirma como la etapa más antigua de explotación de las minas. 


\section{EL PROCESO DE EXTRACCIÓN DE LA VARISCITA}

Aparentemente, el proceso de explotación se realizaba en un sentido ascendente, desde el subsuelo hacia el exterior. Los mineros perforaban verticalmente la roca, hasta los niveles de máxima profundidad según su nivel tecnológico, para después comenzar la extracción de la variscita de abajo hacia arriba. Este sistema de explotación garantiza la seguridad en el trabajo y optimiza la rentabilidad del mismo, ya que facilita la evacuación del mineral extraído. Asimismo, permite el aprovechamiento de la luz natural. Según se iban amortizando los niveles más profundos, estos iban siendo rellenados por el material de procedente de los siguientes niveles (Villalba et alii, 1995).

Se han encontrado abundantes picos de corneana (excepcionalmente de esquisto), que de forma similar a las hachas pulimentadas, estarían enmangados en madera para su utilización como picos mineros en la excavación de pozos y galerías. Presentan una sección elipsoidal y una superficie piqueteada. A veces tienen un encaje o muesca para facilitar el enmangue (figura 2).

Son frecuentes las huellas de estos picos en las paredes de pozos y galerías. Es probable que la roca fuera calentada mediante fuego y rápidamente enfriada con agua, para facilitar la excavación. El mismo procedimiento podría ser usado para extraer el mineral.

Mediante cinceles fabricados en metapodos de buey, con la punta afilada a doble bisel (figura 2), y percutores redondeados de cuarzo (figura 2), se produciría la extracción de la variscita a partir de la veta. También se ha constatado la existencia de palas recogedoras de mango corto, manufacturadas sobre omóplatos de bóvidos (Villalba et alii, 1986, 1995).

La iluminación podría realizarse mediante conchas de bivalvos en las que se colocaría grasa de animal o tuétano con una mecha, para permitir la producción de luz sin humo, aunque no hay ninguna garantía de que esto fuera así. Se nos escapa toda la producción en madera y cestería, que permitiría la fabricación de escaleras para el acceso a las galerías, cuerdas para subir los materiales extraídos y todo tipo de canastos para el transporte del material. Tal vez funcionaran con un sistema rudimentario de polea a base de troncos y cuerdas.

Las galerías, una vez amortizadas del todo, eran cubiertas con material de relleno, a modo de basurero, e incluso, en algún caso, eran utilizadas como lugar de enterramiento.

\section{LA VARISCITA}

\subsection{Historia de un mineral}

La variscita comenzó a aparecer mencionada en las memorias de excavación asociada a contextos neolíticos a partir de las primeras intervenciones arqueológicas. El primer descubrimiento del que se tiene constancia fue un enterramiento en fosa hallado casualmente en Vilanova y la Geltrú el 24 de enero de 1863 e interpretado como una sepultura musulmana, a pesar de pertenecer a lo que más tarde se conocería como Cultura de los Sepulcros de Fosa.

Pronto se perfilaron los collares de variscita como uno de los fósiles guía de esta época, caracterizada por descubrimientos casuales, la mayoría de las veces producidos por 


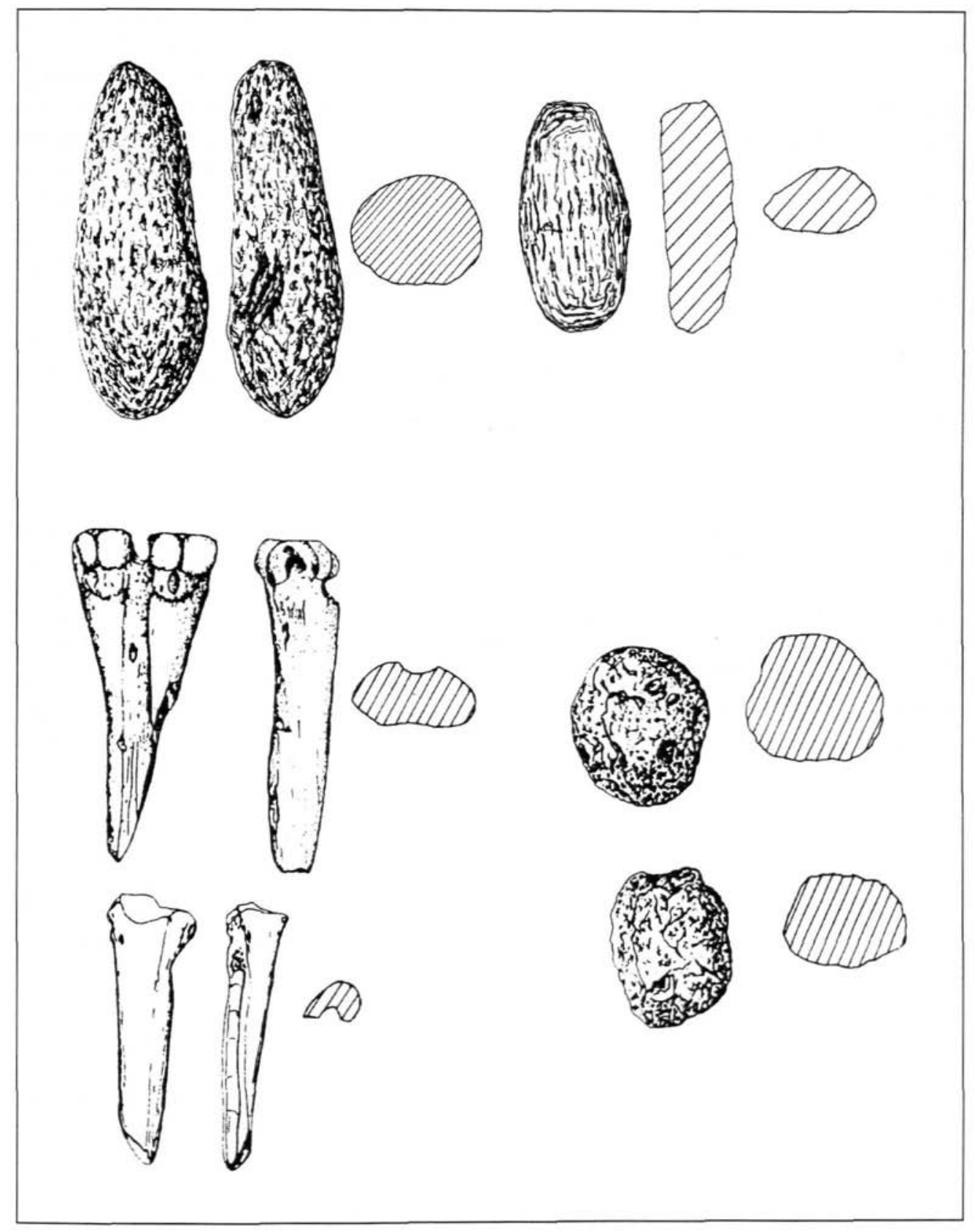

Figura 2. Picos mineros, cinceles y percutores, Neolítico Medio (a partir de ViLALBA et alit, 1986, pág. 177 
labores agrícolas, que los intelectuales del lugar se dedicaron a recoger y a publicar. Aunque más adelante las publicaciones e investigaciones se sistematizaron, el carácter de los hallazgos continuó siendo el mismo, causando uno de los principales problemas que conlleva el estudio de esta cultura en general, y de la variscita en particular, es decir, lo fragmentario de la información recogida debido a su antigüedad, a las frecuentes violaciones o ruptura de los sepulcros, a lo poco sistemático de las excavaciones y a la pérdida de materiales, que tras ingresar en Museos o colecciones privadas, se encuentran hoy en día en paradero desconocido.

Por aquel entonces el mineral era llamado calaíta, término extraído de la obra de Plinio el Viejo. En su Historia Naturalis éste nos indica que:

“...El Callais es de un verde pálido. Hállase en fragmentos voluminosos, pero muchas veces perforados, con cavidades llenas de materias de color castaño. Estas piezas se tallan, pero tienen poca duración. Las más estimadas son de color esmeralda (Optimus colo smaragdi). Cuanto más hermosas son, más aprisa pierden el color por la acción del aceite, ungüentos o vino. Las menos hermosas se conservan mejor. No es fácil de preparar a causa de sus partes vítreas...".

De esta forma la denominación de calaíta, pasó a englobar todas aquellas piedras verdes que tanto en contextos neolíticos como en momentos posteriores acompañaban a los muertos como parte de su ajuar.

En 1864, Damour, adoptando el término propuesto por Plinio el Viejo, identifica la calaíta como un mineral en el que:

"El color es verde aproximándose al verde esmeralda. Algunos ejemplares están matizados de partes blancas y azuladas. Otros están manchados de vetas y motas castañas o negras, en virtud de una mezcla accidental de materias arcillosas. La substancia mineral es traslúcida, poco más o menos como el crisopasio. Su fractura es compacta como de cera. Raya la caliza pero es fácilmente rayada por una punta de acero. El polvo es blanco y su densidad de 2,50 a 2,52. Calentada en un tubo de vidrio a una temperatura un poco inferior al rojo, deja mucha agua que no ejerce reacción sobre el papel tornasol. Decrepita, pierde el color, se torna opaca y toma color castaño de chocolate. En este caso es muy friable" (Damour, 1864 en Muñoz, 1965).

Le da la fórmula de $\mathrm{Al}_{2}\left(\mathrm{PO}_{4}\right) 2 \frac{1}{1 / 2} \mathrm{H}_{2} \mathrm{O}$.

Será Veiga Ferreira (Veiga Ferreira, 1954) quien a partir de una serie de análisis de cuentas de collar en calaíta portuguesa diferencie los diversos minerales que quedan agrupados bajo este nombre. Así nos encontramos con la variscita, un fosfato de aluminio hidratado de fórmula $\mathrm{Al}\left(\mathrm{PO}_{4}\right) 2 \mathrm{H}_{2} \mathrm{O}$ que recibe su nombre de la localidad alemana de Vogtland, y que aparece con mayor frecuencia que otros minerales como la variscita férrica $\left(\mathrm{Al} \mathrm{Fe} \mathrm{PO}_{4}\right.$ $2 \mathrm{H}_{2} \mathrm{O}$ ), la wavelita, la azulita, la malaquita o la turquesa.

En los estudios de M. Llongueras y E. Ripoll en los número XXV y XXX de la revista Ampurias (RIPOLL y LLONGUERAS, 1963 y 1967) se recogen por primera vez todos los datos exis- 
tentes sobre la Cultura Catalana de los Sepulcros de Fosa. La variscita aparece con un destacado papel, atribuyéndosele un origen foráneo, tal vez del norte de África o del Mediterráneo oriental, ya que se desconocía su presencia como mineral explotable en la Península Ibérica (con excepción de Portugal). En aquel momento, a todo aquel material de no clara procedencia, se le asignaba un origen lejano, a ser posible, oriental, dentro de la corriente difusionista, adoptada tras los estudios de Gordon Childe.

Paralelamente a la publicación de este artículo, Ana María Muñoz, que está llevando a cabo su investigación, avanza ya algunas de sus conclusiones en una comunicación presentada al II Symposium de Prehistoria Peninsular (MuÑoz, 1963). Es sin embargo su tesis doctoral, publicada en 1965 y con prólogo de Maluquer de Motes, la que pasa a constituirse como la gran obra sobre la Cultura de los Sepulcros de Fosa.

Muñoz clasifica las cuentas de calaíta en dos formas: las de oliva o tonelete (en las que algunos autores diferencian las cilíndricas) y las discoidales (figura 3). Son más abundantes las primeras, teniendo las discoidales un área de dispersión más definida (comarca de Solsona), aunque aparezcan en algunas ocasiones junto a las de oliva. La autora cuenta exclusivamente con un análisis de una cuenta proveniente de la Bóvila díen Joca (Montornés del Vallés), llevado a cabo por J. Estrada. Asumiendo las limitaciones que esto conlleva, este análisis le permite hablar por primera vez con precisión de la composición mineralógica de las cuentas catalanas, tratándose en este caso de variscita férrica. De esta forma, y por lo parecido de su color y de su fórmula, Muñoz identifica la calaíta con la variscita y sobre todo prevé la existencia de "...filones no muy lejos de donde vivieron los hombres de los sepulcros de fos $a^{\prime \prime}$. No obstante, y debido a lo tradicionalmente aceptado, la autora busca paralelos en las culturas neolíticas orientales. Dos ejemplos del tipo de ajuares de variscita aparecidos en estos sepulcros, pueden observarse en las figuras 4 y 5 .

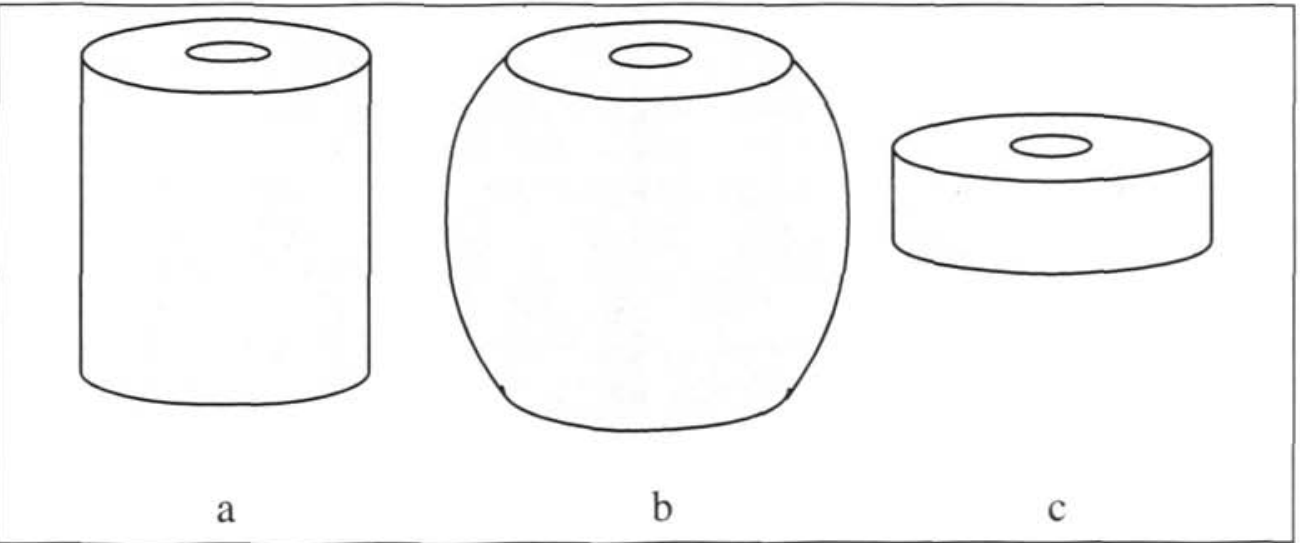

Figura 3. Tipología de las cuentas en variscita:

a) cuenta cilindrica; b) cuenta de en forma de tonelete o de oliva; c) cuenta discoidal (según M. J. NOAIX). 

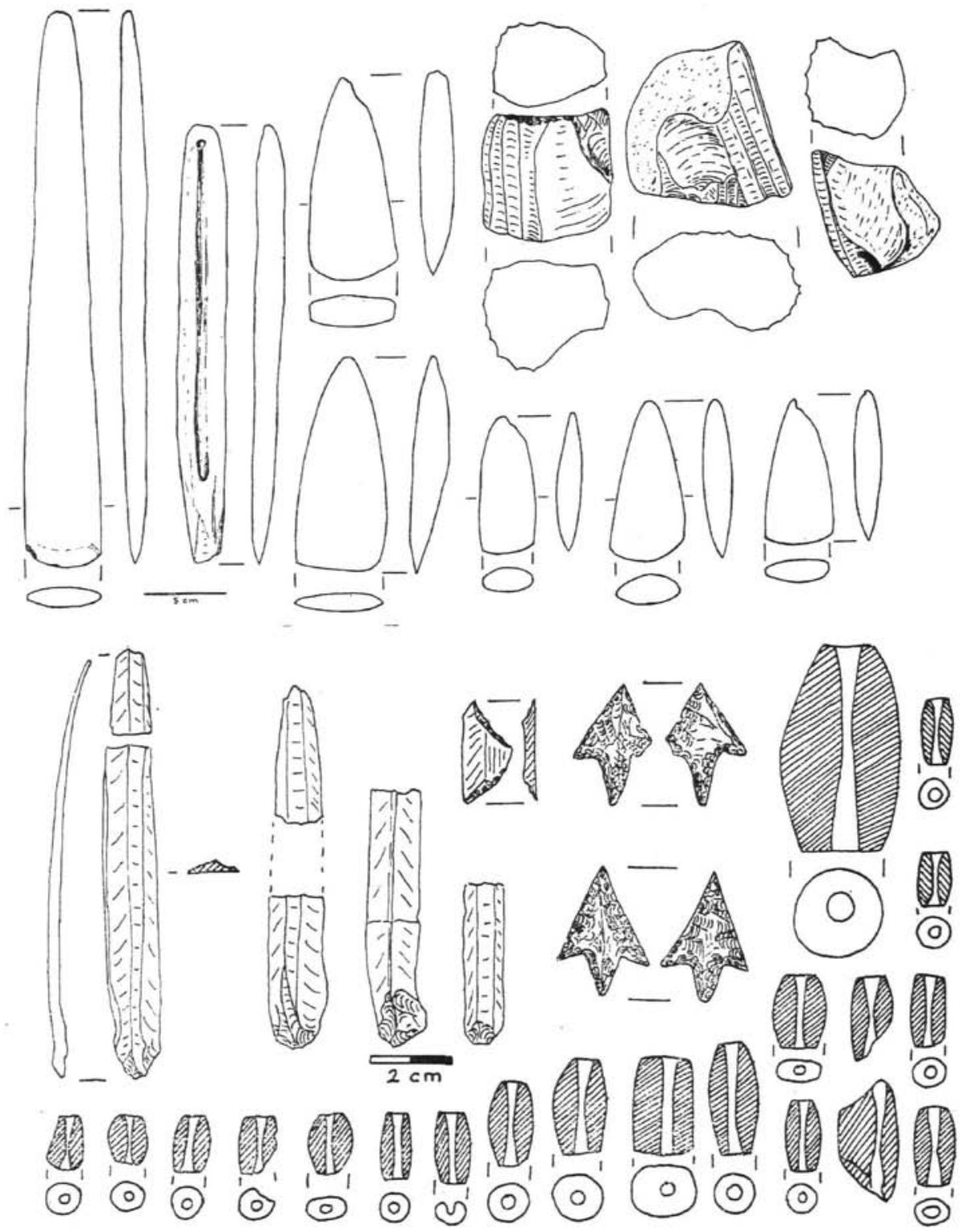

Figura 4. Ajuar de la sepultura de la Bóbila dien Joca (Montornés del Vallés, Barcelona) (a partir de Musioz, 1965, pág. 33 y 34). 


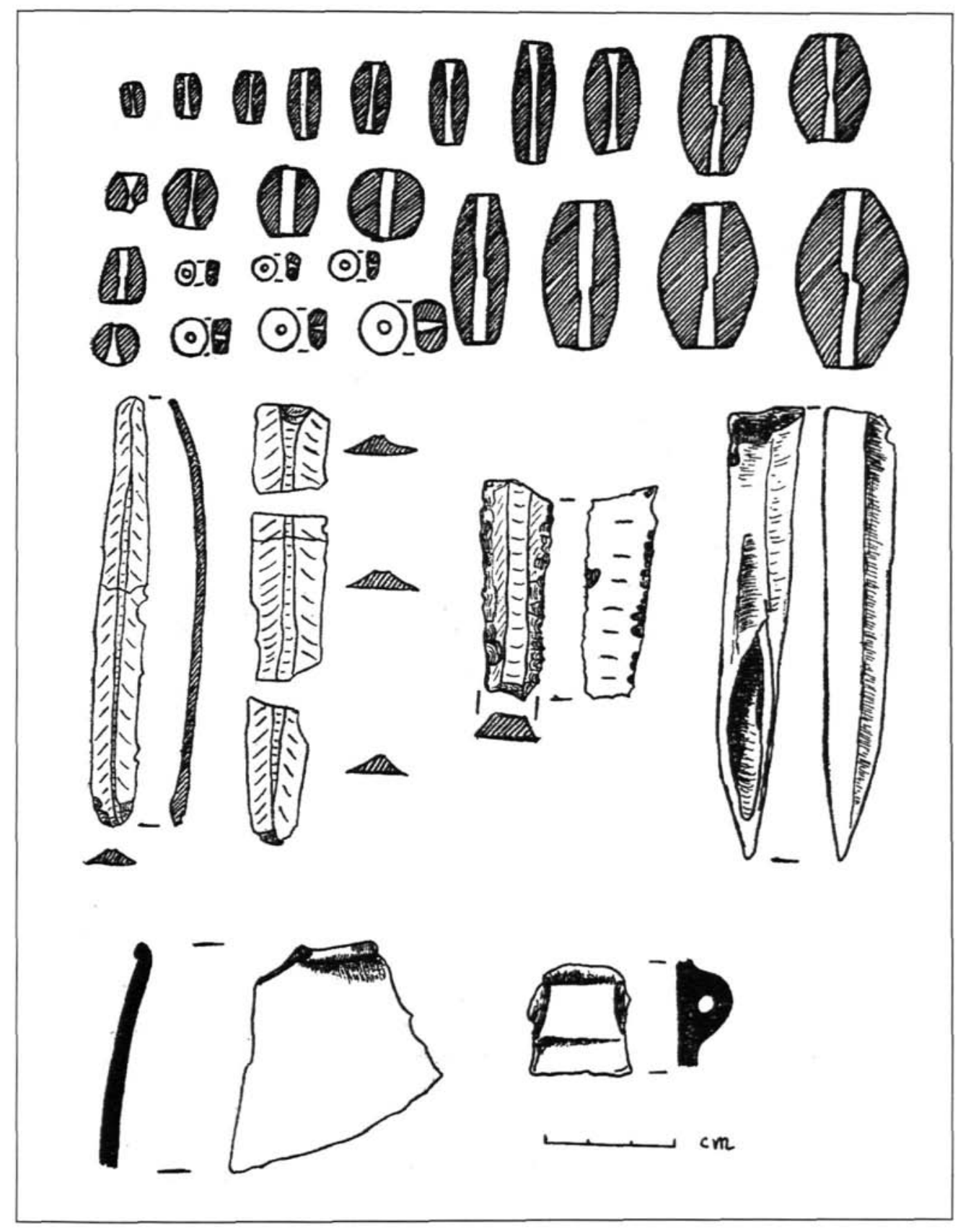

Figura 5. Ajuar de la sepultura de la Bóbila Padró de Ripollet (a partir de Mcĩoz, 1965). 
La variscita se nos presenta entonces como un mineral con una densidad de 4 a 5 , un color verde manzana con diferentes matices hasta el incoloro, tal y como lo define Muñoz a partir de Klochmann (KLOCMANN, RAMDOHR, 1961).

En 1967 Pellicer en el capítulo que dedica al Neolítico Hispano en Las raíces de España, libro coordinado por Gómez Tabanera, recoge la mayoría de las ideas planteadas por A. M. Muñoz en su obra. Atribuye erróneamente un origen foráneo a la calaíta, importada del Mediterráneo Oriental o más bien del sur de Francia, idea, que a pesar de la carencia de datos que lo negaran, Muñoz no había querido dar por supuesta.

Los análisis siguen llevándose a cabo y así nos encontramos con artículos como el publicado por Chantret, Guilaine y Guillemaut en 1970. Aunque los análisis se realizan sobre cuentas de calaíta de monumentos megalíticos franceses, fuera del contexto de los Sepulcros de Fosa, el artículo resulta de gran interés porque nos propone la analítica como método de trabajo fundamental. En los resultados aparecen la variscita, la turquesa, y la malaquita, predominando la primera, como integrantes de la calaíta.

En 1971 Vilaseca escribe una pequeña reflexión en la revista Ampurias sobre el estado de la cuestión de la calaíta, a la que ya denomina abiertamente variscita, pero sin aportar nuevos datos.

En 1977 en el decimoquinto Congreso Nacional de Arqueología se presenta una novedad (Ten CARnÉ, 1977), consistente en un nuevo tipo de cuenta de variscita, llamado cuentacolgante por la forma de lágrima que presenta, con la perforación en el extremo más estrecho. Un depósito de ciento treinta y nueve cuentas fue hallado por el autor en la cueva dels Lladres (Vacarisses, Barcelona), en el interior de una vasija. El conjunto parece atribuible a un Neolítico epicardial, anterior a los Sepulcros de Fosa, lo que lleva hacia atrás la fecha en la que la variscita comienza a utilizarse como materia ornamental (figura 6).

El descubrimiento de las Minas de Can Tintorer en 1972 permite identificar con razonable seguridad la procedencia de la variscita.

En la primera memoria de las excavaciones (Villalba et alii, 1986) se realizan más de veinte análisis mediante difracción de Rayos X sobre muestras de las minas, a través de los cuales, queda por fin confirmado la caracterización de la calaíta como variscita, que junto a su variante férrica y en algunos casos la turquesa, fosfosiderita y strengita, resulta ser el mineral extraído en las minas y repartido por todo el territorio catalán. Ya se citan en este trabajo otros yacimientos peninsulares como el de la Encantada en Almería y el de Palazuelo de las Cuevas en Zamora. Los análisis sobre los filones de las minas y sobre cuentas arqueológicas se ampliarán en la publicación del Congreso de Oporto (EDo et alii, 1995).

En 1991, uno de los miembros del primer equipo de las minas, Manuel Edo, presenta su memoria de licenciatura, que permanece inédita, centrándose en el tema "La calaíta en Cataluña".

Durante 1991 y 1992 se lleva a cabo una exposición denominada "Las joyas en la Prehistoria" en la que nos encontramos con interesantes muestras de collares y brazaletes de variscita, como los de Bobila Padró, Bobila del Negrell, Bovila de Can Vallés, Bóbila Madurell 

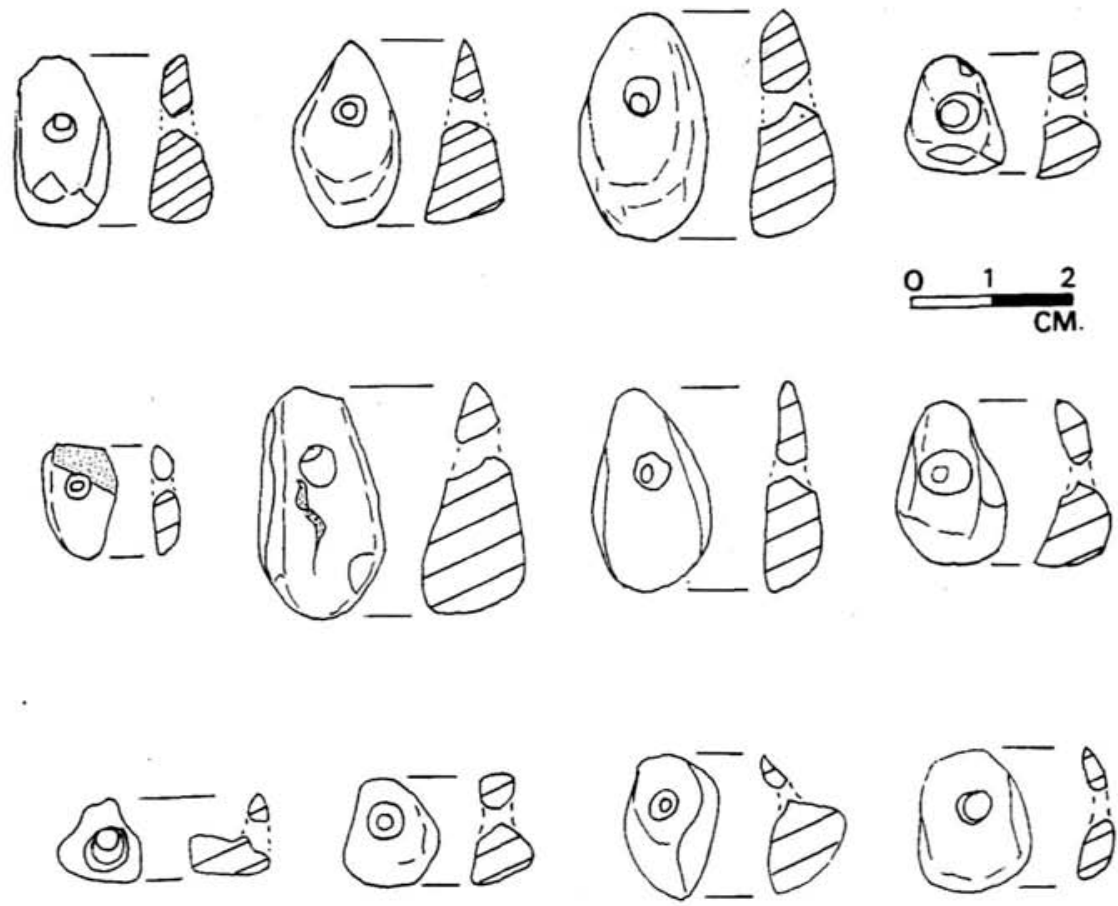

Figura 6. Cuentas colgantes de variscita (a partir de TEx CARNÊ, 1977, pág. 143).

o el collar de cuentas colgante de la Cueva dels Lladres. En la introducción del catálogo publicado (V.V.A.A., 1991) hallamos algunas reflexiones sobre el papel de la variscita y de las minas en la Cultura de los Sepulcros de Fosa.

Paralelamente, van apareciendo artículos centrados en las Minas que aportan nuevos datos sobre este mineral. Así, Edo, Blasco y Villalba presentan en un Coloquio sobre el sílex dos comunicaciones con nuevos datos y análisis (EDO, Blasco y Villalba 1990a y 1990b); Edo analiza la calaíta en las tierras del Ebro en una reunión intercomarcal en Amposta (EDo, 1991); de nuevo Edo, Villalba y Blasco nos hablan de posibles vías de distribución de la variscita en el Homenaje a Maluquer de Motes (Edo, Villalba y Blasco, 1992), con una información que ya había sido tratada en la reunión de Puigcerdá sobre el estado de la investigación en Cataluña, en la comunicación al Coloquio Internacional de Nemours (Villalba, Edo, Blasco, 1991a) o en el Homenaje a Jean Arnal (Villalba, Edo, Blasco, 1991b).

Los últimos artículos aparecidos sobre el tema han sido las comunicaciones presentadas en el Primer Congreso de Arqueología Peninsular de Oporto (EDo et alii, 1995; Villalba et alii, 1995) y en el Primer Congreso sobre Neolítico Peninsular en Gavà (CARDONA et alii, 1996), (BLASCO et alii, 1996). 


\subsection{Las cuentas de collar en variscita de las minas prehistóricas de Gavà}

\subsubsection{Cuentas publicadas por el primer equipo de trabajo}

En la primera memoria de las excavaciones (VILLALBA et alii, 1986) aparece mencionado el hallazgo de catorce cuentas de collar, pertenecientes a las Minas 7, 8, 11, 21 y 28 (figura 7). Respecto a su tipología, nueve son discoidales (1, 2, 3, 6, 7, 10, 11, 12 y 13) y las otras podrían considerarse cilindricas o de tonelete, ya que en este caso la diferencia entre ambas formas es muy sutil $(4,5,8,9$ y 14$)$. La número 8 no está pulida del todo, sino que tiene una sección heptagonal.

En un artículo posterior dedicado a la transformación de la materia prima en Can Tintorer (ARENAS, BAÑoLAS y EDO, 1991) se menciona la realización de análisis a 24 cuentas de collar aparecidas en Can Tintorer en distintos momentos del proceso de fabricación. Las cuentas no aparecen descritas, pero sí dibujadas. Entre ellas se encuentran trece de las catorce cuentas aparecidas en la publicación anterior, más once nuevos ejemplares (figura 8).

Por último, en otra publicación más (EDO, VILLALBA y BLASCO, 1992) vuelve a aparecer el tema de las cuentas de collar en el yacimiento. Esta vez, el contenido del artículo se centra en el análisis de la materia prima de fabricación, para obtener conclusiones sobre el origen y distribución de las cuentas de collar.

De esta manera, en la tabla de análisis aparecen citadas de nuevo veinticuatro cuentas de collar de las Minas de Can Tintorer, con los respectivos resultados de los análisis efectuados. Suponemos que se trata de las mismas cuentas mencionadas en artículos anteriores, pero no lo sabemos con seguridad ya que no aparece ninguna referencia a su tipología ni a su pertenencia a un momento u otro del proceso de fabricación.

\subsubsection{Cuentas pertenecientes a las campañas de excavacion del segundo equipo}

Con la puesta en marcha del "Proyecto de Investigación Minas Prehistóricas" en 1991, se llevan a cabo una serie de intervenciones en el yacimiento, que hasta 1994 quedan a cargo de la Escuela Taller Minas Prehistóricas y que durante el mes de julio de 1995 se continúan con un equipo formado por estudiantes de distintas Universidades. A lo largo de estas campañas aparecieron 192 cuentas de variscita en distintos momentos del proceso de fabricación. Muchas de las piezas fueron recuperadas gracias al cribado con agua que se realizó en todo momento con una criba de $2 \mathrm{~mm}$ de luz.

Las cuentas fueron estudiadas y catalogadas por Alicia Estrada y yo misma durante la campaña de 1995, en el laboratorio del Museo de Gavà. Tras realizar una recogida de datos lo más exhaustiva posible y revisar las cuentas y los fragmentos a través de una lupa binocular, obtuvimos las siguientes conclusiones:

1. Se constataron sistemáticamente diferentes tipos de huellas de fabricación, que pueden observarse en la figura 9:

- Estrías paralelas en una sola dirección en uno o ambos lados (figura 9a).

- Estrías paralelas entrecruzándose en varias direcciones en uno o ambos lados (figura 9b) (lámina I). 


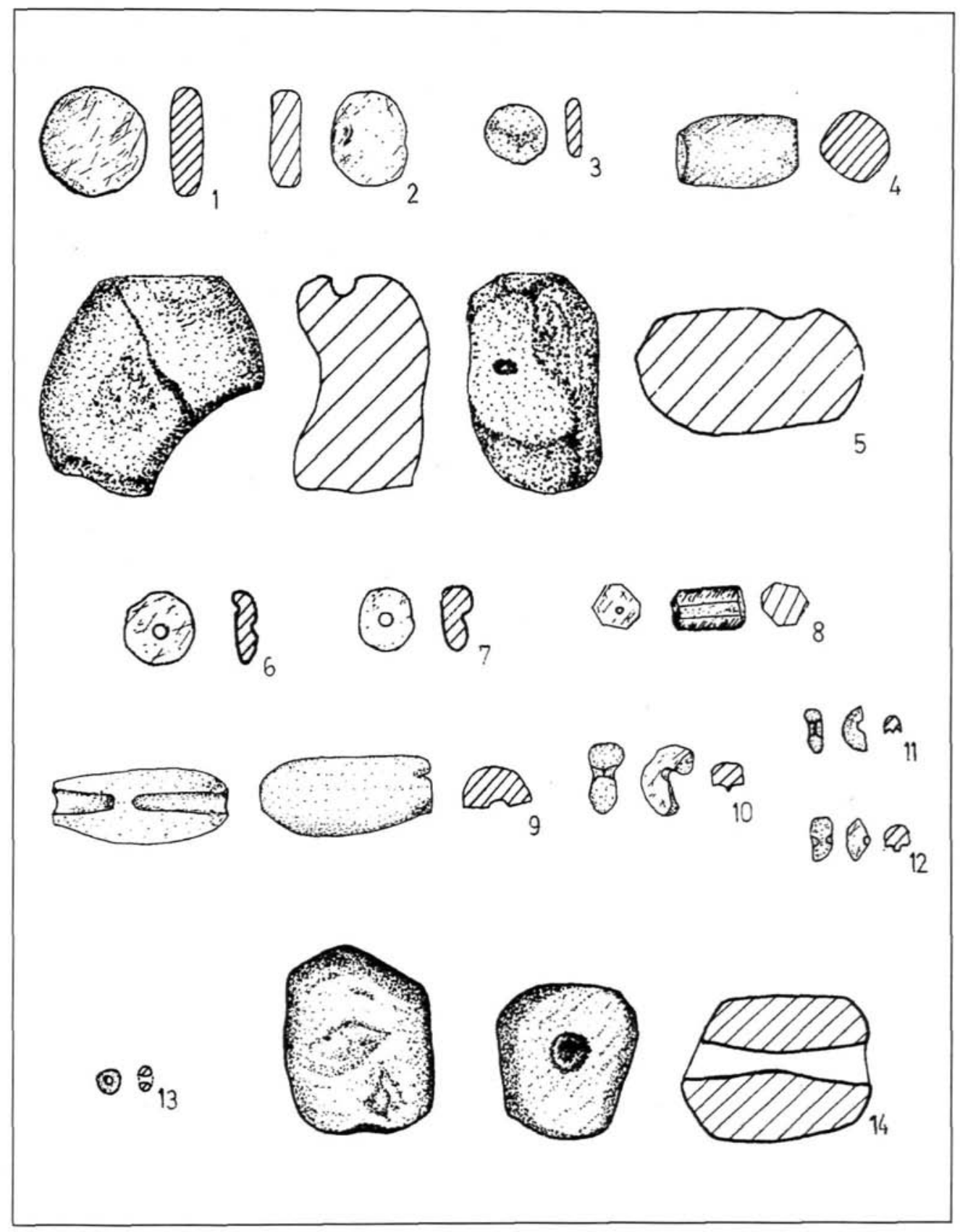

Figura 7. Cuentas de collar en variscita de Can Tintorer (a partir de Vilulba et alii, 1986, pág. 158). 
- Estrías paralelas y oblicuas, en el lateral de la cuenta (figura 9c) (lámina II).

- Estrías paralelas y perpendiculares a los bordes en el lateral de la cuenta (figura 9d).

- Líneas circulares concéntricas en torno a la perforación (figura 9e) (lámina II).

- Brillo en las aristas de la cuenta.

- Brillo en torno a la perforación.

2. La perforación se efectuaba siempre desde las dos caras de la cuenta, encontrándose ambos agujeros a mitad de camino.

3. El momento más problemático del proceso de fabricación, es la perforación, sobre todo cuando los dos agujeros realizados desde ambas caras están a punto de unirse en el centro de la cuenta.

4. Finalmente, se observaron tres tipos diferentes de perforaciones (figura 10), a saber:

- Perforación bicónica (figura 10a).

- Perforación cilíndrica (figura 10 b).

- Perforación en forma de U (figura 10c) (lámina III).
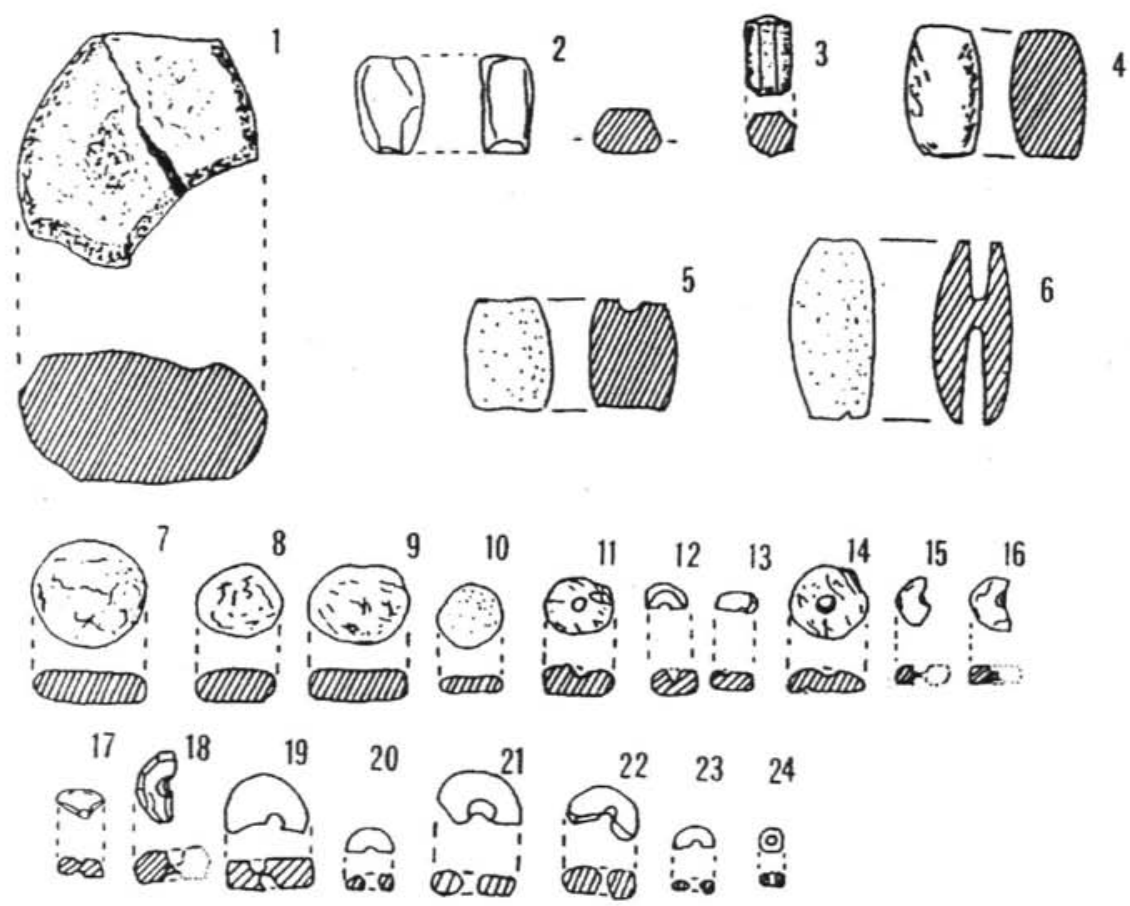

Figura 8. Cuentas de collar de variscita de Can Tintorer (a partir de Aresas, Baśolas y Edo, 1991, pág. 201). 


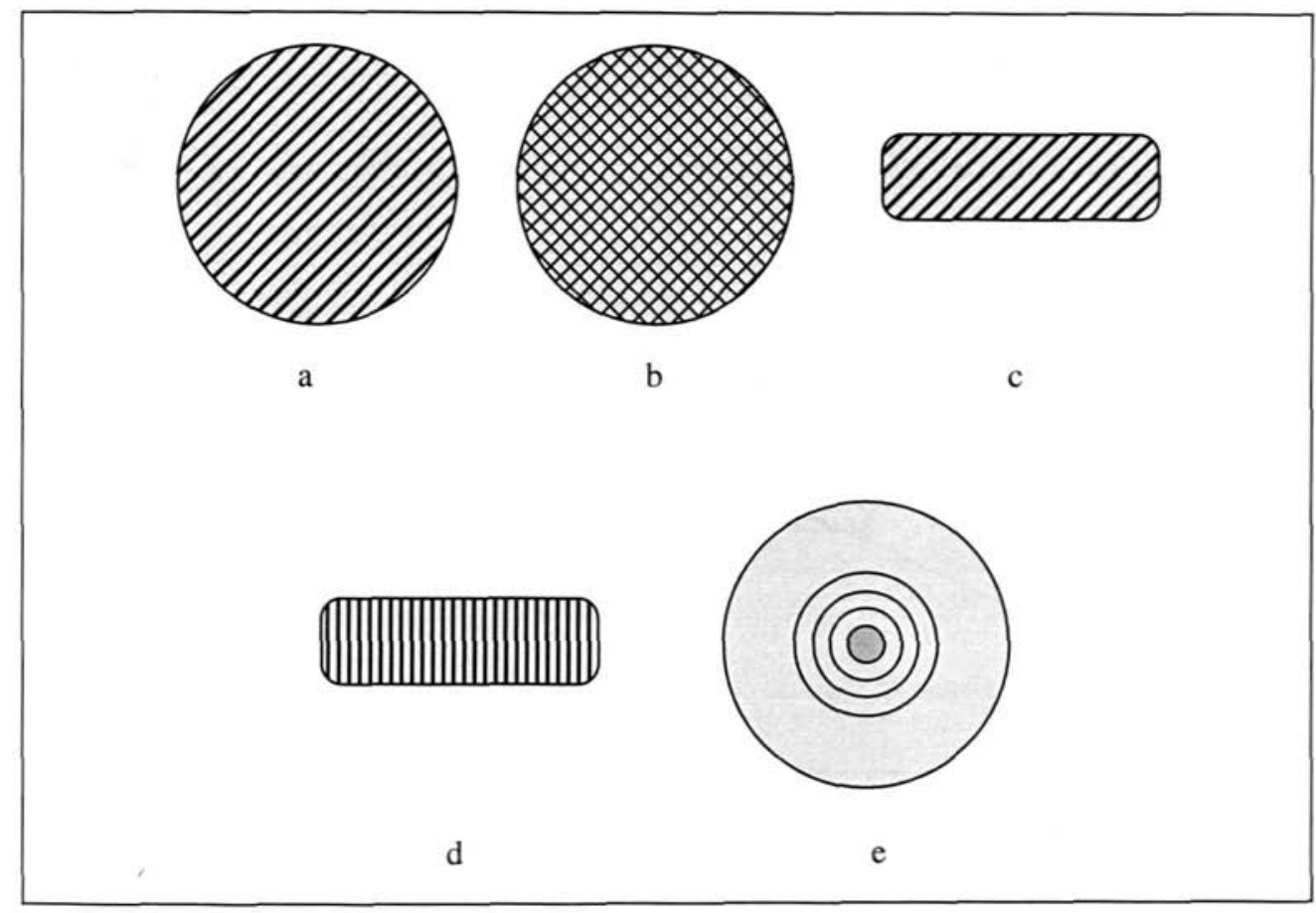

Figura 9. Tipos de huellas (según M. J. NOAIs).

Por otro lado, dentro de la industria lítica y en directa conexión con el proceso de fabricación de las cuentas en variscita, nos encontramos con un grupo de útiles que han sido denominados "brocas". Son piezas de sección circular, a veces poligonal con tendencia al círculo, de muy pequeño tamaño, que aparentemente no están talladas sino pulidas. Parecen estar realizados en sílex, aunque debido a su apariencia pulida no se puede asegurar con certeza hasta que no se hagan análisis al respecto. El primer equipo habla de cuatro ejemplares (EDO et alii, 1995) (figura 11). En las campañas de excavación del segundo equipo catalogamos 10 piezas pertenecientes a esta categoría. Además de las consabidas brocas, aparecieron laminillas en sílex de sección trapezoidal con retoque abrupto por presión en uno o ambos lados. Creemos que estas laminillas serían el paso previo en la fabricación de estas brocas, lo que nos ayudó a la hora de realizar las brocas experimentales.

El grosor de estas piezas coincide con el diámetro de las perforaciones de las cuentas. Este dato y su apariencia hacen pensar que serían los perforadores empleados. Su pequeño tamaño y su forma impiden que fueran manipulados manualmente, por lo que siempre se ha hablado de su inserción en un taladro, como explicamos en el apartado sobre la hipótesis de trabajo.

Toda esta información proporcionó una serie de datos que fueron tenidos en cuenta durante la experimentación y contrastados con los resultados de ésta. 


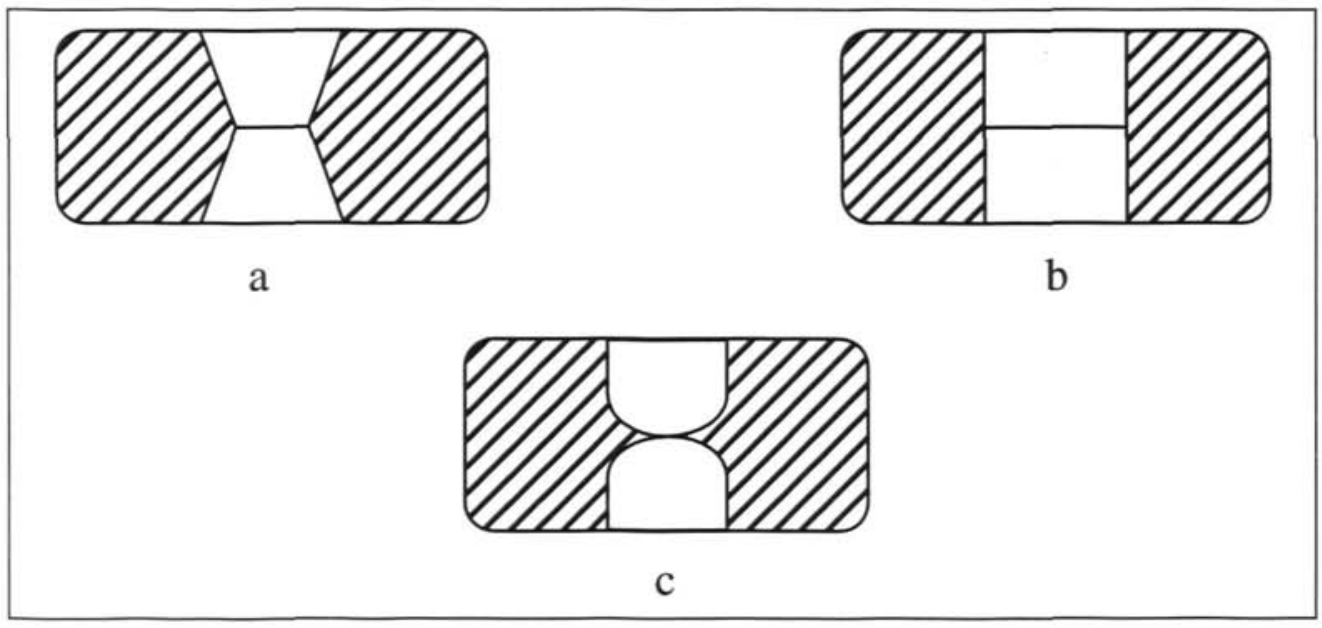

Figura 10. Tipos de perforaciones. Perforación bicónica

(a) perforación cilindrica (b) y perforación en forma de U (c) (según M. J. Noain).

\section{EXPERIMENTACIÓN}

\subsection{La hipótesis de partida}

Para llevar a cabo el proceso de experimentación, se formó un grupo de trabajo, encabezado por el Prof. Javier Baena y con la participación de los estudiantes Oscar Blázquez, Cristóbal Burkhalter, Elena Carrión, Carmen Conde, Pedro Díaz, Sergio Escudero, Gloria García, David González, Germán López, Iván Manzano, Raúl Maqueda, Javier Martín, Jorge Luis Morales, Lourdes Ruiz, Arantxa Sánchez, Sofía Sanza, Alma Urango y Elisa Valero, a quienes agradecemos su colaboración.

Como hipótesis de partida para la realización de la experimentación se tomó el modelo propuesto en la publicación "Les Mines Neolitiques de Can Tintorer" (VIllalba et alii, 1986) y en otros artículos posteriores firmados por el mismo equipo de trabajo. Estos autores proponen un proceso de fabricación basado en los restos materiales aparecidos en el yacimiento, incluyendo cuentas de variscita en proceso de fabricación, cuentas de variscita fragmentadas (trece piezas, en concreto), herramientas de extracción, posibles pulidores y posibles brocas. A estos restos se les añaden los que han ido apareciendo en posteriores publicaciones y los ya analizados en el apartado anterior.

El proceso propuesto consta de las siguientes fases: primero, un desbastado de los bloques extraídos para eliminar las concreciones de pizarra u otros materiales adheridos a los nódulos de variscita mediante un cincel de hueso y un percutor; segundo, una aproximación a la forma de la cuenta a través del aserrado con un buril o de la percusión, para pasar después a un pulimento con un abrasivo de grano grueso; tercero, un pulimento mediante un pulidor de grano fino, cuyo objetivo es obtener la forma definitiva de la cuenta; y quinto, la 
perforación, producida desde las dos caras de las cuentas hasta que ambos agujeros se unen en el centro, mediante un trepanador giratorio de vaivén y sujetando la cuenta con la mano o en un soporte de hueso, madera o piedra (figura 12).

Este hipotético proceso fue puesto a prueba con posterioridad por Arenas, Bañolas y Edo, cuyos resultados fueron publicados en dos artículos de idéntico contenido (ARENAS, Bañolas y Edo, 1991; Arenas y Bañolas, 1989).

Para el pulimento, se ha observado en algunos pueblos primitivos que las cuentas eran ensartadas y pulidas a la vez. Así ocurre con los Indios Pueblo de Santo Domingo en Nuevo Méjico, en otras zonas de América, en Tailandia y en la India. Esta opción no fue utilizada por nosotros, ya que las cuentas de Gavà se pulían antes de ser perforadas, hecho que se constata fácilmente en los fragmentos del yacimiento.

Los autores anteriormente citados se centraron en el trabajo de la perforación y los resultados fueron positivos. Para ello utilizaron un taladro, basado en la rotación alternativa y cuyo origen prehistórico sitúan en la obtención del fuego. Proponen dos modelos: el taladro de arco y el de disco.

El taladro de disco consiste en un palo horizontal de cuyos extremos parten unas cuerdas que van ligadas al extremo superior de un palo vertical. A través de un movimiento de presión ejercido por la mano del usuario, el cordel va enrollándose y desenrollándose sobre el palo vertical produciendo un movimiento de rotación (figura 11, 4c). En el extremo inferior del palo vertical se coloca una placa de madera o piedra como regulador de los movimientos del taladro y de la broca, insertada en la punta. Su funcionamiento se basa en la ley de la inercia. Como mencionan los autores, este tipo de taladro es todavía utilizado por ciertos grupos de primitivos actuales como los indígenas de las Islas Salomon (Oceanía) o algunas tribus de indios de Norteamérica. También ha sido documentado entre los Bosquimanos.

El taladro de arco no se describe en el artículo. Consiste en un vástago de madera vertical sobre el que se enrolla la cuerda de un arco, también de madera, que queda colocado perpendicularmente al vástago, es decir, en posición horizontal. La broca se inserta en el extremo final del palo vertical. Moviendo el arco de atrás hacia delante, el vástago de madera va girando rotativamente en ambas direcciones, produciendo la perforación (figura 11, 4b). El taladro de arco se constata entre los Esquimales, que suelen sujetar la parte superior del taladro con la boca. Ejemplos arqueológicos de taladros de arco aparecieron en el yacimiento neolítico de Balajni y en la cueva Djebel, en Turkmenistán (SEmenov, 1981).

Este tipo de taladro, deja en el perforador usado una serie de círculos concéntricos regulares, en medio de los cuales se halla una protuberancia (bulbo) según observó Semenov. Huellas circulares concéntricas fueron observadas también en las propias perforaciones de las cuentas arqueológicas de Gavà. El autor atribuye este tipo de huellas a perforaciones realizadas desde un solo lado de la pieza (SEmENov, 1981).

Semenov atribuye la invención de estos dos tipos de taladro precisamente a la época neolítica. Según él, esto permitió alcanzar un nuevo nivel en la técnica de perforar la piedra.

Este mismo autor propone un tercer tipo, mucho más sencillo, motivo por el cual el autor lo asocia a tiempos paleolíticos. Podría llamarse taladro manual, aunque es más cono- 
cido como técnica para hacer fuego. Se trata simplemente de un perforador de piedra ensartado en una varilla de madera, que se mueve rotativamente con las palmas de las manos. Este procedimiento no permite usar mucha fuerza, por lo que no ha sido probado en la experimentación (SEMENOv, 1981).

El taladro manual fue también constatado por Yerkes entre tribus del sudeste de Norteamérica, concretamente en la región del Mississippi. Este autor utilizó este método para un trabajo experimental consistente en la reproducción del proceso de manufactura de cuentas de collar en concha. Para esto propone dos sistemas. El primero consiste en apoyar horizontalmente el vástago de madera sobre las piernas, sujetar la cuenta en la palma de la mano izquierda y hacer rotar el taladro, deslizando la palma de la mano derecha sobre éste. Este método resultó ser muy tedioso y lento, por lo que el autor pasó a utilizar el taladro verticalmente, rotándolo con ambas manos, tal y como describe también Semenov (YerKES, 1993).

Este último sistema también fue constatado por Arnold para los Indios Chumash de California (Yerkes, 1993).

En la actualidad, este tipo de taladro es utilizado por las tribus montañosas de Nueva Guinea. Ellos perforan la madera y la piedra sin la sierra de arco aunque la conocen, prefiriendo utilizar este sistema más simple. El perforador es sujetado a la varilla con fibras vegetales. Lo mismo ocurre con los aborígenes australianos (SEMENOv, 1981).

Finalmente, el uso de perforadores manuales en el Neolítico sólo lo atribuye a la realización de pequeños agujeros en objetos de especies pizarrosas blandas.

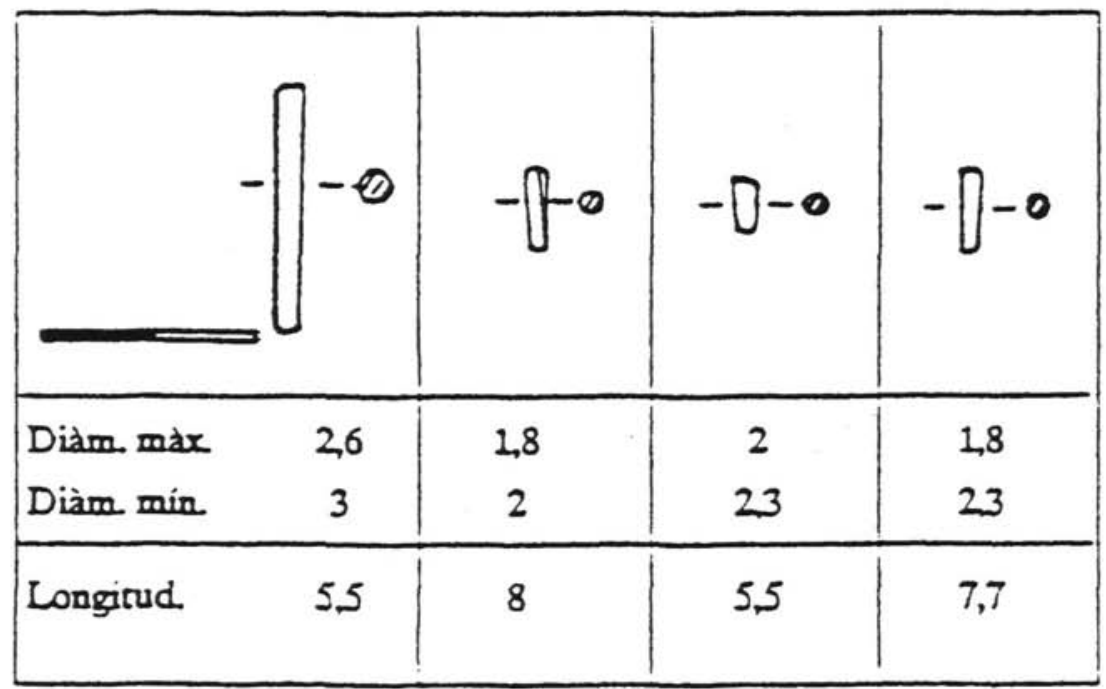

Figura 11. Brocas en sílex (a partir de EDo et alii, 1995). 

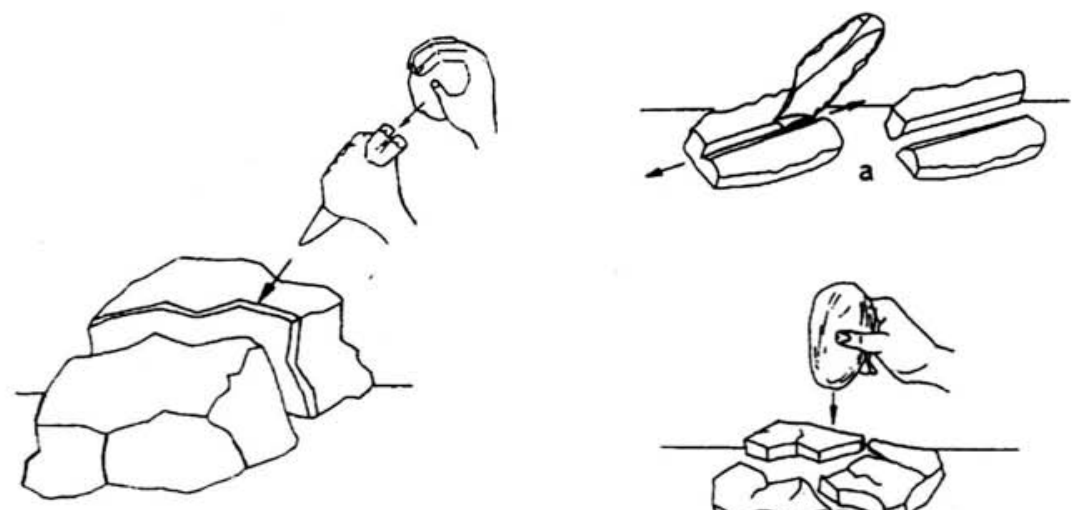

2
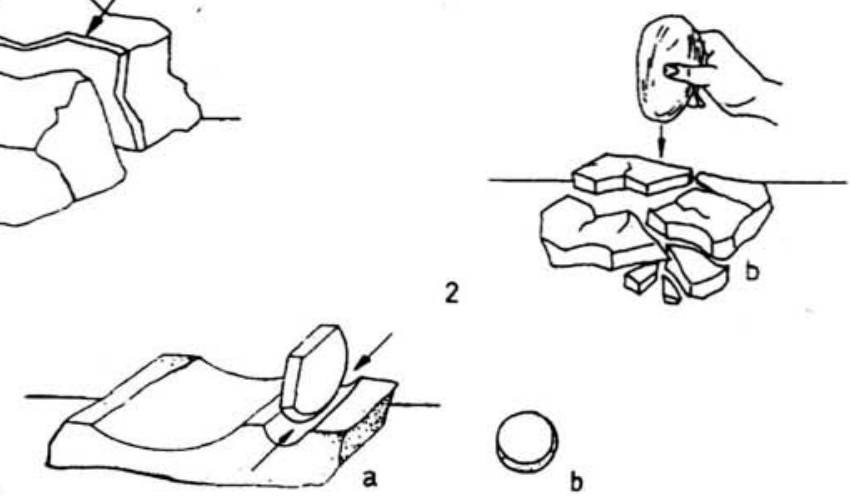

3

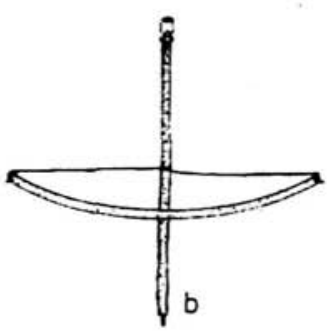

b

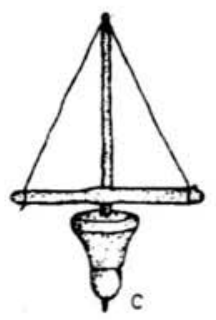

Figura 11. Brocas en sílex (a partir de Edo et alii, 1995).

Las brocas, fabricadas en sílex, se realizaron a partir de microláminas de sección trapezoidal o triangular, facetadas longitudinalmente (es decir, de sección poligonal) a través del pulimento sobre una piedra abrasiva, hasta conseguir el diámetro apropiado. A través de estos útiles las perforaciones fueron realizadas con éxito, pero los autores no especifican en qué proporción, ni los tiempos empleados ni otros detalles de sumo interés.

La perforación se ha de realizar desde los dos lados, ya que esto es algo comprobado en las cuentas arqueológicas. En principio se hace desde uno de los lados hasta la mitad de la pieza para que ambos agujeros se junten en el medio. Semenov, por otro lado, propone la realización de un sólo agujero hasta atravesar la pieza por completo y la regularización de éste, desde la otra cara (SEmenov, 1981). 
Este mismo autor habla en algunos casos del uso de granos de arena de cuarzo humedecidos sistemáticamente como abrasivo.

\subsection{El proceso experimental}

\subsubsection{El pulimento}

Obtuvimos las matrices de variscita del yacimiento de Moncada (Barcelona) en el que no se ha constatado explotación en época prehistórica. Los fragmentos eran restos del trabajo de joyeros actuales, de pequeño tamaño, por lo que no tuvimos más remedio que obviar la primera fase del proceso de fabricación: la obtención de fragmentos a partir de las vetas, su separación de las vetas de pizarra y su desbastado a gran escala. Algunos de los fragmentos presentaban una o ambas caras ya pulidas, por lo que tuvieron que volver a pulirse, para evitar falsas interpretaciones acerca del tiempo de pulido y las huellas de fabricación resultantes.

Otros fragmentos presentaban en muchos casos pequeñas vetas irregulares de color ocre, muy frecuentes en las matrices de variscita y de composición desconocida, ya mencionadas por Plinio el Viejo y por Damour.

Como pulidores se escogieron varios bloques de arenisca y granito. Pudimos disponer de la arenisca propia del yacimiento al final de la época de trabajo. Debido a esto y a que el tamaño de las muestras era pequeño, decidimos no utilizar la arenisca de Gavà, asumiendo que los resultados no serán igual de exactos que si así lo hubiéramos hecho.

Cada uno de los participantes en la experimentación, fuimos tomando distintos fragmentos de variscita y procediendo a su pulimento (láminas IV y V). Las características de esta fase del trabajo fueron recogidas en una ficha e informatizadas, al igual que todo el resto del proceso, en bases de datos de Access.

En total, se empezó el trabajo de pulimento en 44 matrices. De éstas el trabajo finalizó con éxito en 30 piezas, es decir un 68'2\% del total. Las piezas que no se terminaron suponen por tanto el $31^{\prime} 8 \%$ y fueron abandonadas por distintos motivos.

Nueve cuentas se rompieron durante el proceso (20'4\%). De estas nueve, cuatro se fracturaron al pulimentarlas (9'1\%) y las otras cinco se fracturaron al intentar reducir su tamaño mediante la percusión (11'3\%). Dos de ellas (4'5\%), fueron abandonadas por tratarse de un material demasiado duro. La pulimentación no avanzaba y no merecía la pena seguir trabajando sobre esas piezas. Finalmente, las otras tres restantes (6'8\%), iban por buen camino, pero fueron dejadas de lado, por falta de tiempo. Cuando se dio por finalizada la tarea experimental, todavía no se habían terminado.

El principal problema con el que todos nos encontramos, fue el tiempo de pulido. El trabajo era sencillo, pero muy laborioso, haciéndose interminable el conseguir el tamaño buscado para la cuenta. Estos datos pueden observarse en las figuras 13 y 14.

Se optó entonces en algunos de los casos por reducir el tamaño de la variscita a través de la percusión directa, con percutor duro, a veces sobre yunque o con percusión indirecta. 


\section{Proporción de cuentas terminadas y no terminadas}

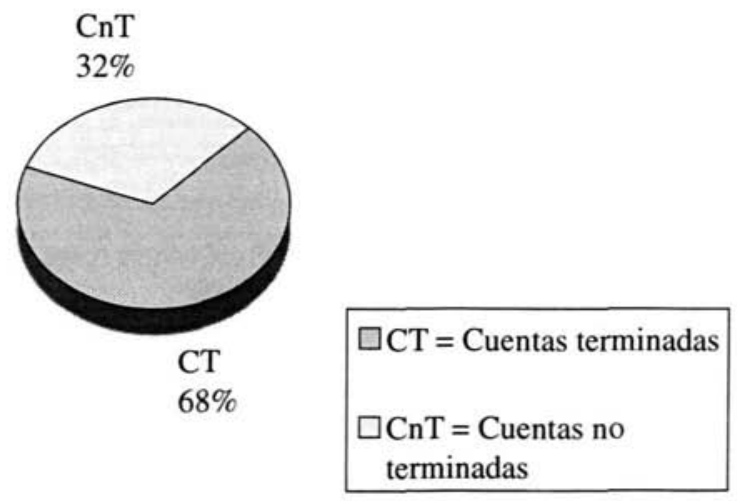

Figura 13. Gráfica del porcentaje de cuentas experimentales terminadas (según M.J. NOAIx)

También en algún caso se usó la presión, con un presionador de asta. La variscita resultó ser fácilmente tallable, presentando una fractura similar a la del sílex. Lo importante era preparar bien el golpe, para evitar que éste se desviara y que la cuenta se fracturara por otro sitio distinto del previsto, echándose a perder la matriz. Para preparar el golpe, se puede realizar una muesca raspando con una lasca de sílex, lo más profunda posible, en el sitio exacto por el que se quiere que la fractura se produzca. El tallado podía realizarse simplemente para eliminar materia o, más definido, para ir dando a la cuenta la forma redondeada.

Otro problema fue la incomodidad del trabajo, ya que según iba reduciéndose el tamaño de la pieza, más costaba sujetarla con los dedos durante el pulimento. En algún caso la cuenta fue agarrada con un trozo de cuero, pero esto dificultaba su manejabilidad. En las cuentas realmente pequeñas, la sujeción era un auténtico problema.

Para solucionar los dos problemas citados (tiempo empleado en el pulimento demasiado prolongado y dificultad para asir la pieza), el Profesor Javier Baena pensó en sujetar el fragmento de variscita a un vástago de madera y así lo hicimos. El fragmento ha de tener un lado más o menos plano para poder ser sujeto. Entonces agarramos el fragmento pegándolo a uno de los extremos del palo de madera con almáciga (láminas VI, VII y VIII).

La almáciga se elaboró mezclando manteca de cerdo con resina de colofonia y ocre. El ingrediente principal era la resina; la manteca y el ocre fueron anadiéndose a discreción hasta obtener la consistencia deseada. Esta ha de estar justo en un punto medio entre el estado líquido y el estado sólido. La almáciga obtenida se calienta cada vez que va a ser utilizada colocándose un poco en el extremo del palo e insertando sobre ella la cuenta. Pronto se solidifica y la cuenta queda bien sujeta. 


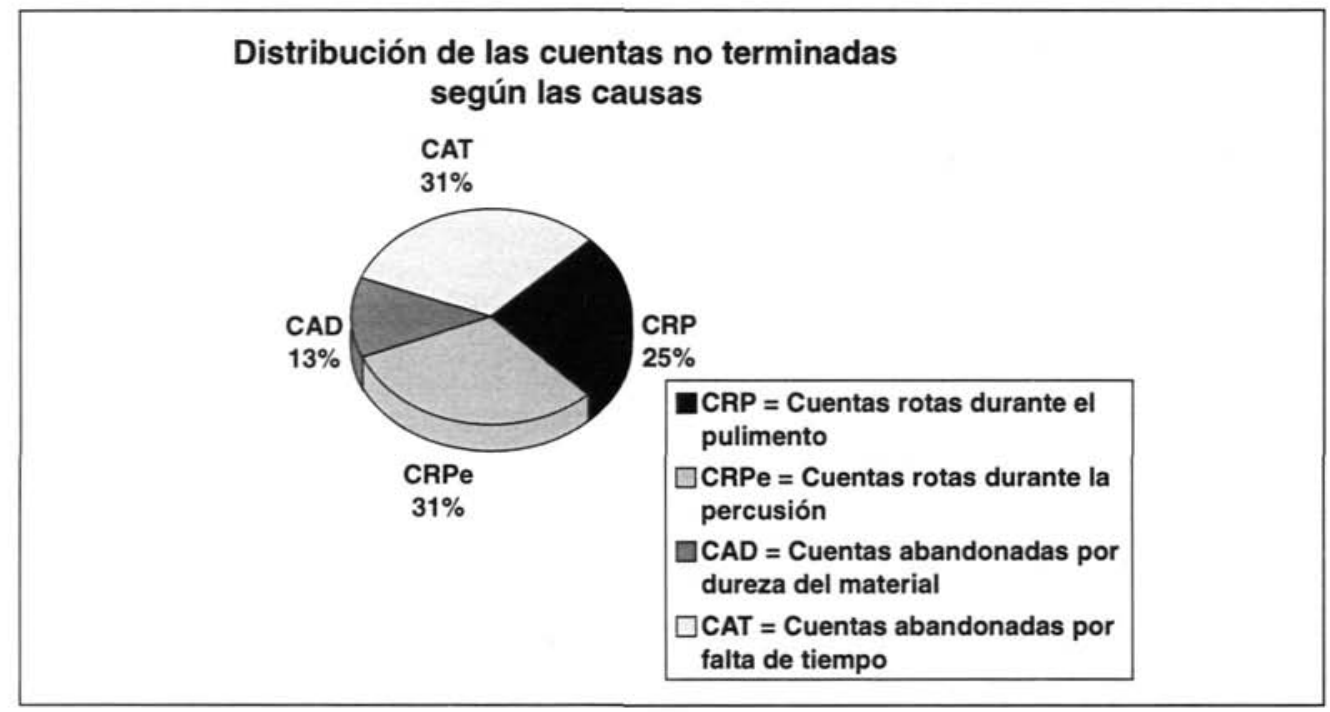

Figura 14. Gráfica de las causas de abandono de las cuentas experimentales durante el proceso de pulimeto (según M.J. Noais)

El trabajo, efectivamente, resultó ser muchísimo más cómodo y al mismo tiempo bastante más rápido. La técnica del enmangado sólo puede utilizarse para reducir el grosor de la pieza, ya que para reducir el diámetro, hay que dar al mismo tiempo forma redondeada a la pieza, lo cual no puede hacerse si ésta está sujeta. Pero aún así la diferencia de tiempo es bastante notable.

El tiempo medio empleado para dar la forma definitiva a una cuenta fue de 2 horas y 15 minutos $^{2}$. Esta media tiene extremos muy diferenciados, ya que el tiempo máximo fue en un caso de nueve horas mientras que en otros casos se tardó tan sólo 25 minutos. Si diferenciamos el tiempo de pulido según las cuentas estuvieran enmangadas o no, los resultados son los siguientes: el tiempo medio de pulimento sin enmangar la cuenta es de 2 horas y media y el tiempo medio de pulido con la cuenta enmangada es de 54 minutos. La diferencia entre un método y otro es más del doble.

Los tamaños obtenidos tuvieron de media 9'4 mm para el diámetro de la pieza y 3'3 $\mathrm{mm}$ para el grosor. La media del diámetro es algo superior a la media de las cuentas arqueológicas, pero no creemos que sea una diferencia significativa.

\subsubsection{Huellas producidas por el pulimento}

Las cuentas fueron observadas por lupa binocular con 16x y 40x. De las 30 piezas terminadas se observaron huellas en 26 ejemplares (87\%). Los tipos de huellas visualizados pueden agruparse en estos tipos (figura 15):

\footnotetext{
${ }^{2}$ Para realizar las medias de tiempo de pulido, sólo se han tenido en cuenta las piezas terminadas.
} 
1. Estrías paralelas en la superficie (figura 15a) (láminas IX y X).

2. Estrías paralelas superpuestas en dos direcciones distintas (figura 15b) (láminas XI y XII).

3. Estrías paralelas superpuestas en todas las direcciones anárquicamente (figura 15c) (láminas XIII y XIV).

4. Estrías oblicuas en el borde de la cuenta (figura 15d) (lámina XV).

5. Estrías paralelas a la arista de las cuentas en el borde (figura 15e).

6. Estrías perpendiculares a la arista de las cuentas en el borde (figura 15f).

7. Brillo.

Las estrías paralelas en una o ambas caras de la cuenta, ya estén presentes en una sola dirección o superponiéndose en dos o más direcciones, son resultado de un pulimento regular, siempre en línea recta, hacia derecha e izquierda o hacia atrás y adelante (láminas IX, X, XI y XII). Es el movimiento más cómodo para pulir la superficie y de ahí que abunde y sea el más común a todas las piezas. Cuando el movimiento de pulido es irregular, es decir, la mano se mueve en todas las direcciones, se producen huellas en línea recta, pero superpuestas unas encima de otras sin orden alguno, como puede observarse en la cuenta número 17 o en la 24 (láminas XIII y XIV). Este tipo de estrías tan irregulares, no se observan en las cuentas de Gavà lo que nos lleva a pensar como una primera conclusión importante que el pulimento se llevaba a cabo de forma regular y organizada, moviendo la mano en una sola dirección; la mano o el vástago de madera, ya que entre las cuentas realizadas de una manera u otra, no se observan diferencias importantes en cuanto al tipo de huellas presentes.

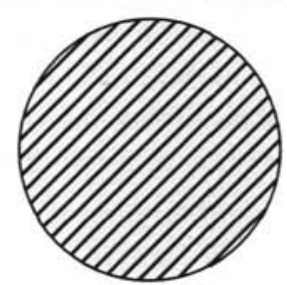

a

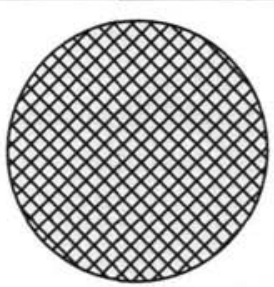

b

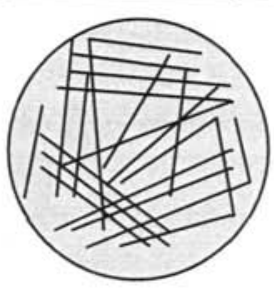

c

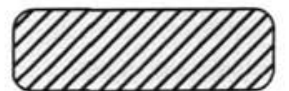

$\mathrm{d}$

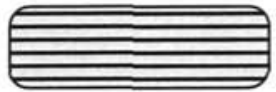

e

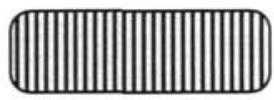

f

Figura 15. Dibujo de los tipos de huellas observadas en las cuentas experiementales (según M.J. NoALx) 
El resultado de las huellas producidas en el lateral de las cuentas, según un tipo de movimiento u otro, pudo ser constatado con mucha exactitud.

Las huellas oblicuas en el lateral son producto de un movimiento regular, también en una única dirección, agarrando la cuenta de tal forma que ésta quede perpendicular a la superficie del pulidor (lámina XV). La cuenta se queda fija y se va desgastando el diámetro en un solo punto. Para conseguir la forma redonda, cada cierto tiempo, se cambia la posición. Estas son las huellas características de las cuentas de Gavà, lo que nos lleva a pensar que éste fue el sistema empleado por los artesanos neolíticos. Este movimiento en la experimentación también produjo en algunos casos (los menos) huellas perpendiculares a las aristas de la cuenta, pero en Gavà no aparece este tipo.

Si colocamos la cuenta también perpendicularmente a la superficie, pero ejercemos un movimiento rotatorio a lo largo del borde, haciendo girar a la cuenta sobre sí misma, se obtienen huellas paralelas o casi paralelas a las aristas de la cuenta. Este tipo de huellas no aparece en Gavà lo que confirma lo dicho en el párrafo anterior. Tiene su lógica, ya que el primer movimiento es más cómodo que el segundo movimiento. Permite ir más rápido y ejercer más fuerza sobre la superficie de la cuenta.

Respecto al brillo no hemos podido constatar su origen, que incluso podría deberse a la manipulación manual de las cuentas. En Gavà también aparece.

Creemos que el análisis de las huellas de fabricación producidas por el proceso de pulimento, ha sido muy fructífero. Ya que nos permite admitir la hipótesis (aunque no con-

\section{Resultados tras el proceso de perforación}

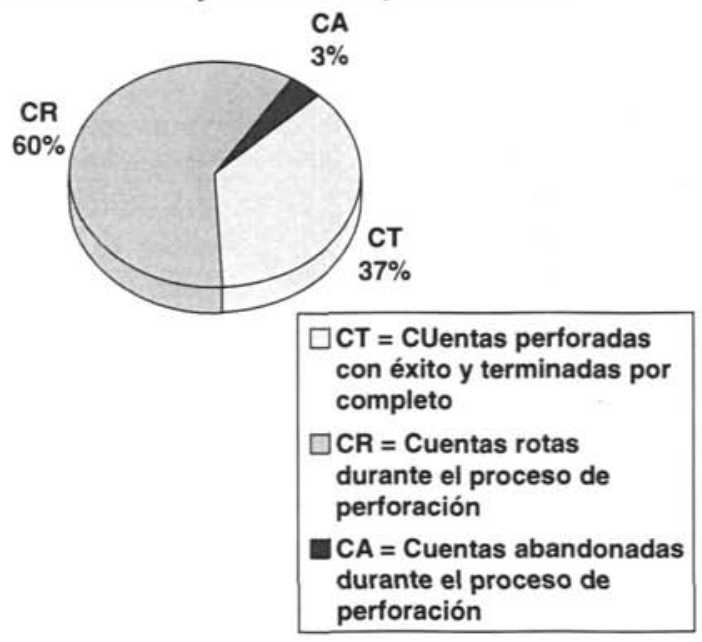

Figura 16. Gráfica de los resultados del proceso de perforación obtenidos en las cuentas experimentales (según M.J. NOAIN) 
firmarla con plena seguridad) de una forma característica de llevar a cabo el movimiento del pulimento, tanto en las dos caras de la cuenta, como en su lateral.

\subsubsection{Conclusiones del proceso de pulimento}

A partir de las observaciones apuntadas por los distintos colaboradores de la experimentación, así como por los datos cuantitativos y cualitativos observados, se pueden extraer las siguientes conclusiones relacionadas con el proceso de pulimentación:

1. Es muy importante la selección de la materia prima. La variscita ha de ser homogénea y no debe presentar vetas de ningún otro material, ya que éstos pueden ser más blandos (en cuyo caso son puntos frágiles) o más duros (en cuyo caso dificultan y retrasan la pulimentación). De la elección de la matriz dependerá en gran parte el éxito del resultado.

2. La variscita, según sea su composición y calidad, presenta diferentes grados de dureza dependiendo de la matriz de la que se trate. Aunque pueda conllevar mayor fragilidad, conviene usar la variscita más blanda, para acelerar el proceso de pulimento. El problema es que esta característica no puede distinguirse a simple vista, o por lo menos no ha sido así en nuestro caso.

3. Hay que intentar que la matriz sea lo más ajustada al tamaño del producto final para reducir el tiempo de pulido. Por este mismo motivo, el uso de la percusión (ya sea directa o indirecta) para reducir el tamaño de la pieza antes o durante el proceso de pulimentación, es muy útil y recomendable. Pero ha de prepararse muy bien y efectuarse con sumo cuidado, para evitar la ruptura de la cuenta.

4. Es bastante difícil que la cuenta se fragmente durante el pulimento, pero es posible. Por ello hay que tener cuidado en no emplear demasiada fuerza, sobre todo cuando el grosor de la cuenta se ha rebajado ya o cuando se observa la presencia de vetas.

5. Lógicamente, se avanza más rápido reduciendo el diámetro de una cara de la pieza, que reduciendo el grosor, ya que para reducir el diámetro la cuenta apoya sobre una superficie menor, siendo, por tanto, la fuerza empleada proporcionalmente mayor.

6. La diferencia entre pulir con la cuenta enmangada y pulir sin la cuenta enmangada es bastante notable, además de ser mucho más cómodo para el artesano. Otra ventaja de esta innovación, es que las dos superficies de la cuenta quedan mucho más lisas, más regulares.

7. El uso de arena y agua como abrasivo, implica una reducción del tiempo de pulido, aunque por los datos obtenidos no parece que ésta sea muy significativa.

8. Hemos visto que el reducir la pieza mediante percusión, el utilizar abrasivos y el enmangar la cuenta, contribuyen a la reducción del tiempo de pulido. Sin embargo, hay otros factores también muy importantes, como son la práctica (cuantas más 
cuentas se hacen, más pericia se va adquiriendo y más se reduce el tiempo de pulido), la fuerza del artesano y la habilidad personal de cada uno.

9. A través de la observación de las huellas producidas, se puede deducir que el pulimento en Gavà se producía en las dos caras a través de un movimiento regular, moviendo la cuenta en una sola dirección, en ambos sentidos.

10. Asimismo, podemos concluir que el pulimento en el lateral de la cuenta se producía de la misma forma, posicionando la cuenta de forma perpendicular a la superficie del pulidor, y moviéndola en una sola dirección, en ambos sentidos. Cada cierto tiempo se giraba la cuenta, para repartir el pulimento por toda la superficie lateral y lograr la forma redonda.

\subsubsection{Las brocas}

El proceso de fabricación de las brocas destinadas a la perforación se recogió también en una serie de fichas.

La materia prima escogida pertenece en su totalidad al área de Madrid, ya que no contamos con sílex propio de la zona de Gavà. La matriz para la extracción de la pieza fue en casi todos los casos una lámina, de la que se extrajo una laminilla. Esta fue retocada por presión, con presionador de asta, generando en casi todos los casos un retoque abrupto.

En algunos casos las piezas se pulieron, siguiendo la hipótesis sugerida por el análisis de las brocas arqueológicas. Este resultó ser un trabajo bastante incómodo, por la dureza del sílex y por el pequeño tamaño de las matrices. Finalmente optamos por sujetar las brocas con almáciga a un vástago de madera, tal y como hicimos al pulir las cuentas, para facilitar su manipulación. En algunos casos se utilizó polvo de sílex empastado con agua como abrasivo. Ninguna de las brocas pulidas quedó tan perfectamente redondeada como las brocas arqueológicas, pero es muy posible que de haber seguido más tiempo con el pulimento, habrían acabado adquiriendo esa forma.

\subsubsection{Los taladros}

Los taladros fueron confeccionados por el Profesor Javier Baena, siguiendo las dos tipologías mencionadas en apartados anteriores: el taladro de disco y el taladro de arco. Los vástagos de madera no fueron confeccionados experimentalmente, sino que se compraron, ya que creemos que la fabricación de los taladros no forma parte de los datos que necesitamos para la experimentación. Sería otro asunto a tratar. Lo mismo sucedió con las cuerdas, ya que se usó hilo de bramante comercializado.

En la base de los taladros, justo antes del lugar en el que se inserta la broca, se pusieron unas pesas para con su peso dar al taladro la inercia necesaria para enrollarse y desenrollarse. En algunos casos se utilizó una plaquita circular de pizarra de unos $10 \mathrm{~mm}$ de espesor. En otros se colocó un trozo de madera, también circular, pero de más altura, para equilibrar los pesos. De todas formas resultó mucho mejor el peso de pizarra, ya que permite el enrosque de la cuerda con muchísima facilidad. 
Los taladros han de sujetarse por su parte superior para mantener su perpendicularidad. Pueden utilizarse también sueltos, sólo con la mano derecha, pero son mucho más inestables y su trabajo es muy irregular. Para sujetarlos, utilizamos unas plaquitas de madera, con una pequeña hendidura circular en la que se acoplaba el taladro.

De esta forma, los taladros de disco (para las personas diestras) se sujetan verticalmente con la mano izquierda y se accionan con la mano derecha, moviendo ésta de arriba a abajo, para permitir el enrolle de la cuerda. Los taladros de arco, funcionan igual, pero el movimiento de la mano derecha es justo el contrario, de adelante a atrás. La cuerda tiene que estar muy tirante, si no el taladro no gira bien.

Las brocas son insertadas en el extremo inferior del vástago vertical. Para ello se hizo una perforación en este con un berbiquí. Se insertaron las brocas y luego fueron afianzadas con almáciga e hilo de bramante atado a su alrededor.

\subsubsection{La perforación}

En palabras de Semenov:

"El origen de este procedimiento [la perforación] está vinculado a la necesidad de unir dos o más objetos, tanto herramientas de trabajo como adornos que se colocan sobre el cuerpo del hombre. Parece ser que la perforación de objetos de piedra para usarlos como adornos precede a su uso en herramientas" (SEMENOV, 1981).

Para este autor el taladrado constituye una de las grandes conquistas de la Prehistoria.

Para comenzar a perforar la cuenta es necesario primero hacer una muesca que permita que la broca agarre en la superficie. Si no, está baila y el taladro se sale continuamente de la superficie de la cuenta. La muesca puede hacerse con una lasquita de sílex o con un buril. Puede rascarse la superficie, provocando una pequeña hendidura; presionar con un extremo afilado o en los casos más difíciles utilizar la percusión indirecta. En este último procedimiento, se apoya el extremo afilado de una lasca justo en el centro de la cuenta y se golpea suavemente el extremo contrario de la lasca con un percutor. Este sistema puede resultar muy útil, pero ha de realizarse con mucho cuidado.

De las 30 cuentas que terminaron de pulirse sólo se perforaron con éxito 11. Los porcentajes pueden observarse en la figura 16.

El tiempo medio empleado en realizar la perforación (cifra obtenida exclusivamente de los tiempos de las cuentas terminadas) es de 1 hora y 45 minutos. Si en esta media, no tenemos en cuenta los tiempos de la cuenta $n^{2} 1$ (se alejan notablemente de la media) la cifra obtenida es de 1 hora y 30 minutos.

El tipo de perforación obtenida se ha podido observar en aquellas cuentas que se han partido por la mitad, esto es, de las 30 cuentas en las que se inició la perforación se ha podido definir en 24 ejemplares. Nos encontramos con tres tipos de perforaciones distintas: perforación cilíndrica, perforación troncocónica y perforación en forma de U (lámina XVI), idénticos a los descritos para las cuentas arqueológicas (figura 10). Los porcentajes según el tipo de perforación (excluyendo las cuentas en las que no se llegó a realizar ésta) pueden observarse en la figura 17. 


\section{Distribución de las cuentas según el tipo de perforación}

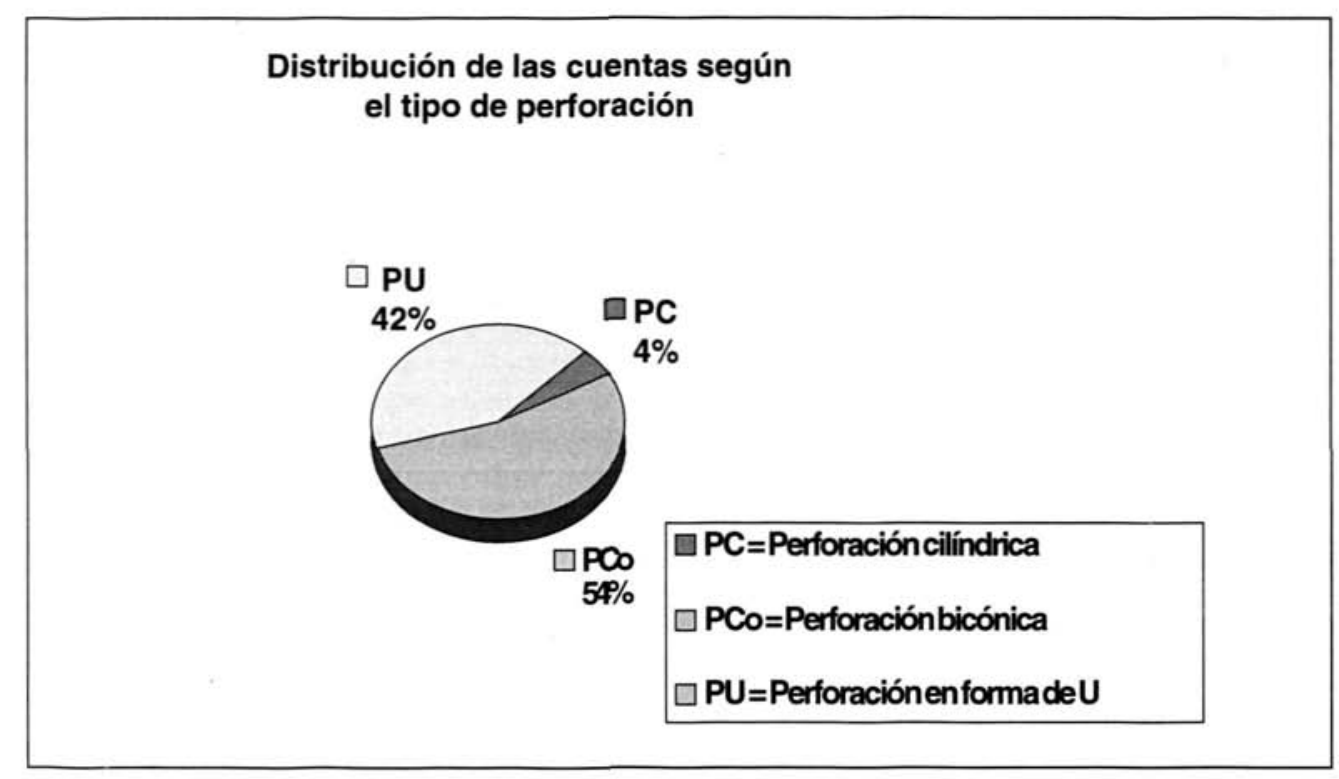

Figura 17. Gráfica con los tipos de perforación (según M.J. NoArN)

No hemos conseguido establecer ninguna relación entre el tipo de perforación obtenida y alguna de las variables empleadas en la experimentación. Creemos que las diferencias pueden deberse al tipo de broca y al comportamiento de ésta en relación con la calidad de la variscita, aunque, como acabo de decir, no lo hemos podido comprobar.

\subsubsection{Huellas producidas por la perforación}

Todas las cuentas, fueran perforadas con éxito o no, fueron revisadas con lupa binocular. Los casos en los que no pudieron verse ningún tipo de huellas eran en su mayoría cuentas que se rompieron antes de iniciar la perforación o cuentas que tenían atravesada la zona de la perforación por una de esas vetas de color marrón que muchos de los fragmentos de variscita presentaban.

Sólo se constató un tipo de huellas: estrías circulares concéntricas producidas en las paredes de la perforación (figura 18) (lámina XVII). Estas se observaron en planta en cuentas terminadas y en sección en cuentas que se partieron por la mitad. En todos los casos, las huellas eran muy similares, a pesar de que la perforación se hubiera realizado con distintas brocas o la calidad de la variscita fuera diferente.

La apariencia de estas huellas experimentales es exactamente igual a las huellas presentes en las perforaciones de las cuentas arqueológicas. En estas últimas, los círculos concéntricos también eran las únicas huellas producidas por el proceso de perforación. 


\subsubsection{Conclusiones del proceso de perforación}

A partir de los datos obtenidos durante el proceso de perforación de las cuentas experimentales hemos podido extraer las siguientes conclusiones:

1. Puede decirse que la perforación manual es prácticamente imposible. Tal vez en alguna pieza especialmente blanda puede llegar a realizarse tras muchas horas de inversión de trabajo, pero en general, no parece viable.

2. La confección de las herramientas de trabajo es importantísima y va a condicionar en gran medida el éxito de la perforación. Los taladros han de estar equilibrados y han de tener el peso correcto para permitir su función. Tanto el taladro de disco como el taladro de arco se mostraron operativos, pero el primero de ambos resultó ser de más fácil manejo, más cómodo de usar y más rápido.

3. La tipología de las brocas también es fundamental. Eduardo Ramil, a quien agradecemos su sugerencia, nos recomendó usar una laminilla, de sección triangular, sin retocar y sin pulir, con los bordes en vivo. Pero este sistema no parece operativo: los biseles de las brocas, cuando existen y están muy afilados, permiten avanzar más rápido en la ejecución de la perforación; pero por otro lado se mellan y se desgastan muchísimo, pudiendo "desaparecer" la broca por completo en unos momentos. Por este motivo es mucho mejor retocar y pulir las aristas y la punta. Así, el trabajo va más lento, pero es mucho más seguro. La broca aguanta mucho más, es más difícil que se rompa y perfora de forma más regular.

4. Una posibilidad es combinar ambos tipos de brocas según el momento de la perforación y según el tipo de materia prima. Con la variscita blanda conviene usar las brocas pulidas, ya que al ir más lentas, el trabajo se controla mejor. Con la variscita dura, es muy difícil iniciar la perforación, por lo que pueden ser útiles en ocasiones las brocas con aristas, ya que aunque éstas se desgasten rápidamente, permiten afianzar el inicio de la perforación. En cualquier caso si se quiere obtener rentabilidad de una broca y realizar un trabajo más seguro, ésta ha de pulirse.

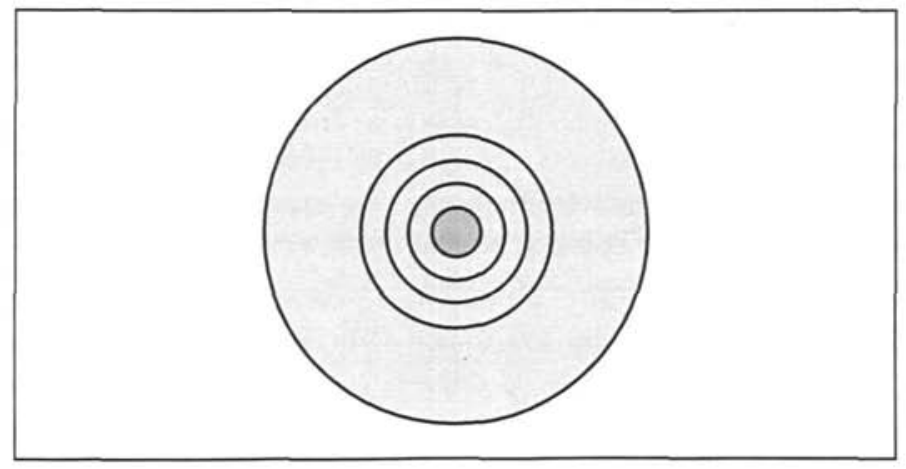

Figura 18. Huellas concéntricas en torno a la perforación (según M.J. NOAIs) 
5. Esta observación ya fue constatada por Semenov, quien comenta que cuando se produce con un perforador un movimiento rotativo en ambos sentidos los bordes cortantes del perforador se embotan muy rápidamente (SEmENov, 1981).

6. Es mejor usar una broca estrecha, ya que profundiza más y el agujero queda más pequeño y más estético. El tamaño de las brocas arqueológicas es idóneo para esto.

7. Perforan mejor las brocas que tienen el extremo apuntado que las que lo tienen redondeado o romo.

8. Otro aspecto importante del trabajo es sujetar correctamente la broca al taladro. La broca tiene que estar perfectamente vertical respecto a la superficie de la cuenta. De no ser así, el taladro baila y no se puede manejar correctamente. Además el agujero sale torcido. Por otro lado, tiene que estar muy bien sujeta. En los casos en los que no pudimos agarrarla bien (la punta del taladro más eficaz, después de varias horas de uso, fue deteriorándose rápidamente y la sujeción de la broca fue un problema), perdimos muchísimo tiempo recolocando la broca, cada vez que está perdía su estabilidad. El tiempo real de perforación aumenta mucho si se le suma el tiempo empleado en recolocar la broca, cambiar el bramante a los taladros (se rompe con bastante frecuencia), calentar la almáciga, etc.

9. Los taladros pueden usarse sujetados con una plaquita de madera en la que se acopla el vástago vertical o sin sujeción. Ambas formas funcionan, pero es más segura la primera. Si el taladro no se sujeta, baila mucho y la perforación sale mucho más ancha y de forma ovalada.

10. Es bastante normal que las brocas se rompan. Cuando esto ocurre, suelen partirse exactamente a la altura en la que están enmangadas, con un corte recto, limpio y perpendicular al eje de la broca. Para evitar esto; hay que intentar no ejercer demasiada presión sobre el taladro con las manos.

11. El trabajo de perforación genera mucho calor. Por este motivo la almáciga que sujeta la cuenta suele reblandecerse y hay que esperar a que endurezca o volverla a fijar.

12. La muesca necesaria para iniciar la perforación requiere bastante cuidado. En algunos casos, fue muy difícil de realizar por la dureza de la variscita; en algún otro, el uso de la percusión indirecta, provocó la ruptura de la cuenta. Primero ha de intentarse hacer la muesca simplemente raspando con una lasca de sílex. Si entonces se comprueba que la pieza es muy dura, se ha de intentar con la percusión, pero no antes.

13. El uso de polvo de sílex empastado con agua como abrasivo acelera el proceso de perforación. De todas formas, la diferencia sólo se aprecia en algunas cuentas y tampoco es demasiado significativa.

14. Es muy fácil que la perforación quede descentrada. La broca busca el sitio más cómodo para avanzar, y aunque se haya señalado el centro de la pieza con la 
muesca realizada al inicio, la broca se desplaza fácilmente. Una vez desplazado el inicio del agujero, es prácticamente imposible rectificarlo. El agujero del otro lado, entonces, ha de hacerse también descentrado para intentar que ambos coincidan.

15. El realizar una perforación desde ambos lados tiene una clara función práctica, ya que ayuda a intentar evitar la ruptura de la cuenta. Además tiene una función estética, ya que una perforación realizada desde un único lado queda demasiado ancha por un lado y demasiado estrecha por el otro, causando una perforación totalmente asimétrica.

16. Una vez que las dos perforaciones se han unido, conviene dejar de usar el taladro y pasar a ensanchar la perforación final con un perforador o una microlasca, manualmente.

17. La perforación de forma cónica o bicónica no implica (tal y como ya nos lo comentó Manuel Edo en comunicación oral) el uso de una broca de forma cónica. Aunque la broca sea perfectamente cilíndrica, el movimiento de rotación provoca que sea más ancha en el punto de inicio que en la mitad de la cuenta.

18. Como última conclusión, y coincidiendo con lo dicho para el pulimento, tal vez lo más importante de todo el proceso de fabricación, sea la selección de la materia prima. La variscita escogida ha de ser muy homogénea y no presentar el más mínimo rastro de otros materiales, fácilmente perceptibles por el cambio de color. Durante la perforación, en cuanto se tropieza con una veta de otro material, la cuenta se rompe siguiendo la línea de la veta. Por otro lado, hay que intentar, dentro de la variedad de durezas, escoger una matriz blanda, para acelerar el proceso de pulimento y perforación. Si la variscita es muy dura, la broca en vez de perforar realiza una pequeña concavidad que se va puliendo cada vez más, impidiendo su avance hacia abajo.

\subsection{Conclusiones sobre el proceso de experimentación}

\subsubsection{Resultado de la experimentación}

El primer resultado final que podemos mencionar es que de todas las matrices en variscita que se empezaron a trabajar, el $25 \%$ llegaron a su forma definitiva de cuenta de collar completa.

En principio el resultado parece descorazonador, ya que solamente una de cada cuatro cuentas trabajadas pudo ser terminada. Pero creemos que existen algunos factores que contribuyeron a reducir el porcentaje de cuentas terminadas:

1. La materia prima. Ya hemos mencionado varias veces lo importante que es la correcta selección de la variscita para su trabajo. Hay que recordar que los fragmentos que empleamos eran restos de talla de joyeros actuales y que muchos presentaban vetas, las principales responsables de la ruptura de las cuentas tanto durante el proceso de pulimento como durante el proceso de perforación. 
2. Las condiciones del trabajo en grupo, sin el cual habría sido imposible realizar este trabajo, pero que conllevan el hecho de que muchas veces una misma pieza pase por diferentes manos. Es necesario conocer las características concretas de cada cuenta para trabajarla, y este hecho lo dificulta.

3. Y finalmente, nuestra condición de "hombres y mujeres del s. XX", que no puede compararse con la habilidad que tendrían los hombres y mujeres de Can Tintorer a la hora de trabajar la variscita, gracias a una familiaridad muy superior a la nuestra con la materia prima y las herramientas de trabajo.

\subsubsection{Tiempo de fabricación}

El tiempo de trabajo empleado para la realización de las cuentas, sólo puede ser medido, lógicamente, en aquellas cuentas finalizadas por completo. Por tanto, sólo tenemos once ejemplares, a partir de los cuales obtener tiempos de fabricación. Según los datos recogidos, obtenemos un tiempo medio de realización por cada cuenta de 4 horas. Si excluimos los datos de la cuenta $\mathrm{n}^{2} 1$ (que se salen de los tiempos comunes) la media corresponde a 3 horas y cuarto.

A estos datos hay que anadir el correspondiente tiempo dedicado a la fabricación de las brocas y de los taladros (habría que dividir el tiempo empleado en fabricar una broca o un taladro entre el número de cuentas que se hubieran realizado con dicha broca o taladro, por lo que no creemos que en este sentido el tiempo total de trabajo aumentara mucho) y el tiempo empleado en preparar la almáciga, sujetar la broca al taladro, reacomodar ésta, etc.

Teniendo en cuenta la pericia que suponemos tendrian los explotadores de las Minas de Gavà, los tiempos reales se reducirían. De hecho, hemos podido comprobar que cuantas más cuentas fabrica una persona, menos tiempo tarda en realizarlas. Es por esto, que aunque en un principio todo el proceso experimental ha parecido tremendamente costoso, si analizamos los datos objetivamente los tiempos invertidos en la manufactura de las cuentas no son tan altos como en un principio podía parecer.

\subsection{3. ¿Es válida nuestra bipótesis de experimentación?}

Ahora vamos a pasar a enumerar aquellas características que hemos observado son iguales en las cuentas arqueológicas y en las cuentas realizadas experimentalmente:

1. El porcentaje de cuentas rotas, que en un principio parece tan descorazonador, es un dato a favor para validar la viabilidad de la experimentación. Es cierto que se han roto muchas cuentas, pero también es cierto que en el yacimiento aparecen muchas cuentas rotas. Aunque personalmente habría sido más estimulante poder terminar todas las cuentas sin problemas, esto habría sido peor a la hora de comparar los dos procesos, el arqueológico y el experimental.

De todas formas no podemos hablar de cifras, ya que carecemos del dato referido al número de cuentas que empezaron a trabajarse en el yacimiento, por lo que no podemos comparar los porcentajes de éxito. Sin embargo, en apariencia, las cifras de cuentas rotas parecen ser altas en ambos casos. 
2. La comparación del tipo de huellas producidas por la fabricación de las cuentas nos parece de vital importancia a la hora de comparar los resultados. En lo que respecta al pulimento podemos afirmar que las huellas de las cuentas del yacimiento son muy similares a las producidas durante la experimentación. Tanto las estrías paralelas en la superficie de la cuenta (ya sea en una única dirección, en dos direcciones distintas o en varias direcciones, superpuestas de forma más o menos anárquica) como las estrías oblicuas o paralelas al borde en los laterales, aparecen repetidamente en las cuentas arqueológicas y en las cuentas experimentales.

3. Todo lo dicho respecto a las huellas producidas por el pulimento, puede aplicarse a las huellas producidas por la perforación. El único tipo constatado, estrías circulares concéntricas en las paredes de la perforación, aparece a menudo en ambos tipos de cuentas, con una apariencia casi idéntica.

No hemos visto en las cuentas arqueológicas un brillo característico que aparece en algunos ejemplares del Can Tintorer. Pensamos que es posible, por tanto, que este brillo sea producto de las condiciones de enterramiento accidental de las cuentas.

4. Dentro del grupo de las cuentas arqueológicas, nos encontramos con que la forma más común en que se fragmenta una cuenta arqueológica, es la que se produce por la mitad de ésta durante el proceso de perforación. Esto ha ocurrido también en lo que respecta a la experimentación. El tipo de fractura es realmente muy similar.

5. En las cuentas arqueológicas se han constatado tres tipo de perforaciones: cilíndricas, bicónicas o bitroncocónicas y en forma de U. Estos tres tipos aparecen tal y como son en la experimentación. Los porcentajes no son exactos, ni mucho menos, pero en ambos casos el tipo de perforación más frecuente es el bicónico.

Somos conscientes de que, por muy satisfactorios que sean los resultados de un trabajo experimental, nunca se va a poder llegar a afirmar, con completa seguridad, que ese fue el procedimiento empleado en tiempos prehistóricos.

Sin embargo, los cinco puntos mencionados creemos que aportan datos suficientes como para dar por operativamente válido el proceso experimental aquí propuesto. El método funciona, las cuentas se perforan y cuando no es así, como ya hemos remarcado repetidas veces, pensamos que es más un problema de la materia prima que del propio método en sí. Los pulidores han resultado funcionales, las brocas de sílex han podido perforar las cuentas gracias a unos taladros que han funcionado rápida y cómodamente. Y no sólo esto. Además de comprobar que la hipótesis experimental es válida, las huellas obtenidas, tanto en pulimentación como en perforación, el tipo de fractura y los tipos de perforaciones obtenidos son tan similares a los arqueológicos que nos permiten pensar con bastante seguridad que los trabajadores de las Minas Prehistóricas de Gavà siguieron el mismo método de trabajo que hemos seguido nosotros.

\section{CONCLUSIONES}

Desde que se descubrió el primer sepulcro de fosa en 1863 hasta nuestros días ha pasado más de un siglo en el que el conocimiento sobre esta cultura ha ido ampliándose pau- 
latinamente. La atención que esta cultura ha despertado en los investigadores ha permitido avanzar los estudios en este sentido. Contrariamente a lo que sucede con la mayoría de ellas, conocidas por sus hábitats y no por sus costumbres funerarias, la cultura de los Sepulcros de Fosa, tal y como su nombre indica, pasó a definirse por un tipo de enterramiento y unos ajuares característicos, siendo estos últimos los que caracterizaron la cultura material.

Dentro de estos ajuares llamaron la atención algunos hechos singulares, como la riqueza y complejidad de algunos de ellos (ver ejemplos citados en la página siguiente). También destacó la evidencia de unas relaciones a larga distancia con culturas contemporáneas como la de Chassey o la de Lagozza y la presencia de materiales excepcionales como era el caso del sílex melado o de las cuentas de collar en variscita. Mucho tiempo permane. ció así el estado de la cuestión hasta que en los últimos veinticinco años, gracias al descubrimiento de las Minas, fuente de abastecimiento de la variscita, y a la excavación de yacimientos de habitación, el conocimiento de esta cultura del Neolítico medio se amplió notablemente.

Contamos ahora con datos sobre la cultura material de la vida cotidiana, el tipo de hábitat, la economía y aspectos técnicos sobre la explotación de la variscita. Sin embargo, y aunque quedan multitud de aspectos por cubrir en los campos descritos hasta ahora, donde realmente se nos plantean preguntas de todo tipo es en lo que respecta al tipo de sociedad que caracterizaba a esta cultura.

Pocos autores han abordado en conjunto el contexto social de los Sepulcros de Fosa. Por un lado nos hallamos ante grupos supuestamente agrícola-ganaderos que viven en poblados sencillos (fondos de cabaña) sin aparentes sistemas defensivos y sin datos suficientes como para pensar en la existencia de unas actividades artesanales complejas ${ }^{3}$. Por otro lado, nos encontramos con un momento avanzado cronológicamente, en pleno Neolítico medio, y unos enterramientos con grandes diferencias de ajuares y presencia de individuos infantiles dotados de ajuar. Como muestra de ello, ponemos dos ejemplos escogidos por la abundancia y calidad de los elementos de sus ajuares:

\begin{tabular}{|c|c|c|c|}
\hline \multicolumn{4}{|c|}{ BOBILA D'EN JOCA (Montornés del Vallés, Barcelona): Materiales de ajuar } \\
\hline Industria lítica & Cerámica & Variscita & Otros \\
\hline $\begin{array}{l}\text { - Dos puntas de flecha de sílex con aletas y } \\
\text { pedúnculo. } \\
\text { - Una punta de flecha de filo transversal. } \\
\text { - Fragmentos de } 4 \text { cuchillos de sílex melado. } \\
\text { - } 3 \text { núcleos de sílex melado "pata de cabra". } \\
\text { - Dos esquirlas de sílex. } \\
\text { - Seis hachas de piedra pulimentada, una de } \\
\text { ella de } 34 \mathrm{~cm} \text { de longitud. }\end{array}$ & $\begin{array}{l}\text { - Fragmentos } \\
\text { de un vaso de } \\
\text { cerámica. }\end{array}$ & $\begin{array}{l}-21 \text { cuentas de } \\
\text { collar. }\end{array}$ & $\begin{array}{l}\text { - Un alisador de } \\
\text { diorita. }\end{array}$ \\
\hline
\end{tabular}

‘ Hay que recordar que sólo se han excavado tres hábitats: la Bóbila Madurell, la Feixa del Moro y Ca N'Isac. 


\begin{tabular}{|c|c|c|c|}
\hline \multicolumn{4}{|c|}{$\begin{array}{l}\text { SEPULTURA RECTANGULAR DE LA BOVILA PADRO (Ripollet, Barcelona): } \\
\text { Materiales de ajuar }\end{array}$} \\
\hline Industria lítica & Industria ósea & Cerámica & Variscita \\
\hline $\begin{array}{l}\text { - Un cuchillo del silex gris. } \\
\text { - Un cuchillo de sílex melado. } \\
\text { - Un cuchillo de sílex melado fragmentado. } \\
\text { - Un núcleo de obsidiana. } \\
\text { - } 5 \text { núcleos de sílex melado "pata de cabra". } \\
\text { - Seis hachas de piedra pulimentada. }\end{array}$ & $\begin{array}{l}\text { - Un punzón } \\
\text { de hueso. }\end{array}$ & $\begin{array}{l}\text { - Fragmentos } \\
\text { de un vaso } \\
\text { de cerámica. }\end{array}$ & $\begin{array}{l}\text { - } 261 \text { cuentas } \\
\text { de collar. }\end{array}$ \\
\hline
\end{tabular}

Como contraste aquí tenemos otros dos ejemplos en el extremo contrario:

\begin{tabular}{|l|}
\hline $\begin{array}{l}\text { SEPULTURA DE LA URBANIZACIÓN BATLLORI (Badalona, Barcelona): } \\
\text { Materiales del ajuar }\end{array}$ \\
\hline Cerámica \\
\hline - Pequeño vaso de cerámica. \\
\hline
\end{tabular}

\begin{tabular}{|l|}
\hline $\begin{array}{c}\text { SEPULTURA DE COLILLIS (Joval, Lérida): } \\
\text { Materiales del ajuar }\end{array}$ \\
\hline Industria ósea \\
\hline- Gran punzón de hueso \\
\hline
\end{tabular}

Además de los ajuares, a la hora de juzgar la riqueza de los enterramientos habría que tener en cuenta el tiempo empleado en la elaboración o construcción del propio sepulcro. Evidentemente no requiere la misma inversión de trabajo una fosa simple que una cista recubierta en su interior por lajas y tapada por un pequeño túmulo de piedras. El comprobar si existe una correlación entre el tipo de ajuar y el tiempo invertido en la construcción de la tumba, sería un aspecto interesante que se escapa del ámbito de este trabajo.

Si intentamos aplicar algunos de los planteamientos clásicos de la Arqueología de la Muerte al grupo cultural de los Sepulcros de Fosa, los resultados son bastante descorazonadores, siempre debido a un sesgo en la información disponible, a causa de la ausencia de estudios antropológicos (recuérdese que la mayoría de las excavaciones son antiguas, por lo que de muchos de los enterramientos no se conserva más que el cráneo) lo que impide intentar relacionar los tipos de ajuar con la edad y el sexo de los inhumados. Los únicos estudios 
que han intentado seguir este camino son los realizados en la Necrópolis de la Bóbila Madurell. En este caso, nos encontramos con dos interpretaciones distintas: primero, la de aquellos autores que no ven una relación entre los ajuares, el sexo y la edad, observando cierta homogeneidad en los enterramientos (ALAMINOS, BLANCH y LázARO, 1991) y los que ven una relación clara entre estos elementos (MERCADAL, VIVES, 1991). Los primeros explican las diferencias en función de unidades familiares más o menos económicamente independientes. Los segundos establecen una diferenciación entre las tumbas femeninas, masculinas e infantiles, pero no explican a qué criterio puede deberse esto o a qué estructura social puede corresponder.

No parece observarse una relación entre el ajuar y la posible actividad productivo-económica del difunto, ni siquiera para separar el trabajo masculino del femenino. Lo que está claro es la existencia de una diferencia cualitativa y cuantitativa en la composición de los ajuares. Tanto los más ricos como los más pobres aparecen en los enterramientos de mujeres y hombres adultos y en los infantiles.

Respecto a este punto, cabe mencionar la opinión de Alekshin, según el cual la existencia de enterramientos ricos no implica necesariamente la existencia de una estratificación social, ni siquiera en el caso de la presencia de tumbas infantiles con importantes ajuares. Los enterramientos infantiles dotados de ricos ajuares pueden ser producto de las costumbres religiosas y de determinados rituales. Por otro lado, la presencia de ricos ajuares en las tumbas femeninas puede deberse a diferencias establecidas según la edad y el sexo. Según Alekshin, sólo se puede hablar de sociedad estratificada cuando se constata una clara diferencia de ajuares entre las tumbas masculinas, siendo algunas de ellas considerablemente más ricas que la media del resto (AleKshin, 1983).

Por otro lado, estos enterramientos presentan una homogeneidad en un territorio muy amplio como es la actual Cataluna, llegando incluso a Aragón, lo que parece indicar una unidad cultural, representada entre otras cosas por la presencia de cuentas fabricadas en Gavà, lo que demuestra la existencia de unos circuitos comerciales y/o de redistribución bien defi-

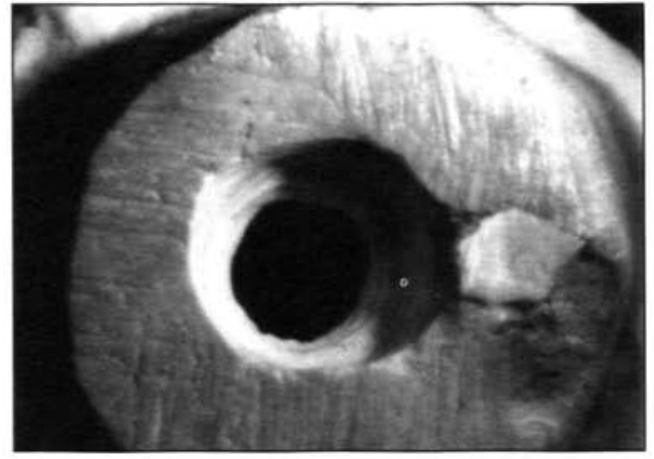

Lámina I. Cuenta arqueológica. Estrias paralelas entrecruzindose en varias direcciones sobre la superficie de la cuenta y estrias circulares concéntricas en torno a la perforación.

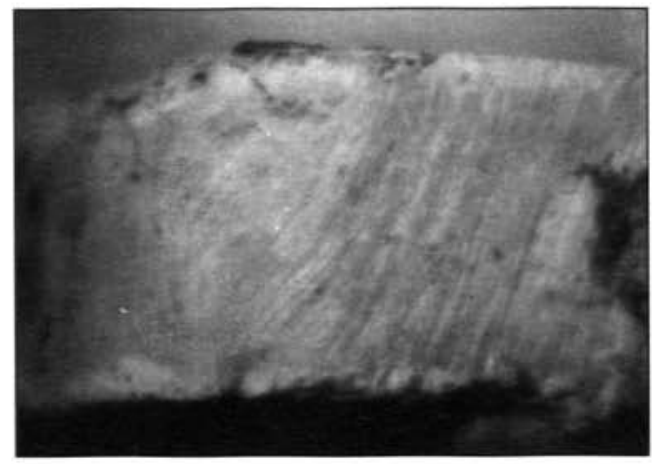

Lámina II. Cuenta arqueológica. Estrias oblicuas en el lateral de la cuenta. 
nidos. No hay que olvidar que los enterramientos de los Sepulcros de Fosa suponen el primer rito funerario estandarizado del Neolítico, que incluso podría ser el punto de arranque del megalitismo catalán. Esto implica una clara diferencia respecto a grupos neolíticos anteriores y grupos contemporáneos de otras regiones, que solamente presentan enterramientos aislados en contadas ocasiones (por ejemplo, el enterramiento de la Cova de la Sarsa) (CASANOVA, 1978). Se trata de una cultura mucho más homogénea que las existentes en estos momentos en Levante o Andalucía y por supuesto, diferente al mundo cardial ${ }^{4}$. La Cultura de los Sepulcros de Fosa siempre se ha considerado como un periodo en el que se afianzan las actividades productoras. Este desarrollo de la agricultura sobre todo, pudo conllevar un mayor arraigo al territorio y una cristalización de las creencias religiosas en la plasmación de una necrópolis estable.

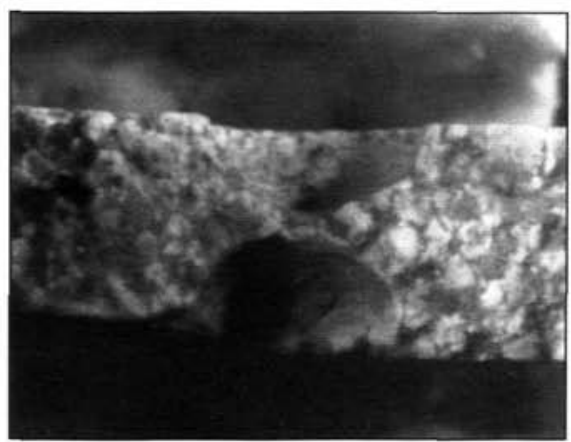

Lámina III. Cuenta arqueológica. Sección de una perforación con forma de U.

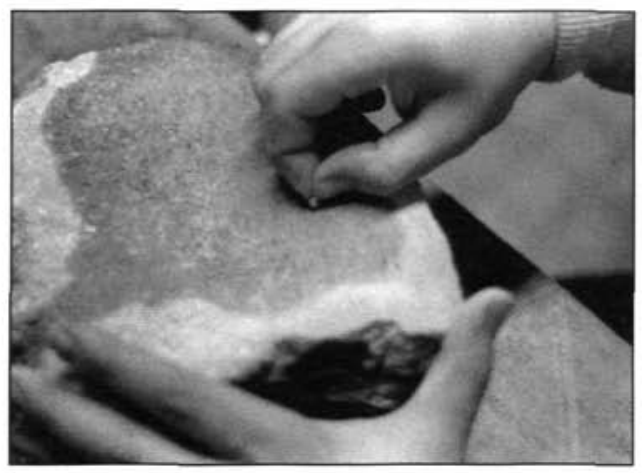

Lamina IV. Pulimento experimental de una cuenta.

Para Vicent:

“...el fenomen arqueològic més clarament relacionat amb la institucionalització de l'apropaicó dels mitjans de producció és l'inici de les pràctiques funeràries sitemàtiques. La relació entre aquestes i la constitució de grupos locals de filiació és úvbia [...].

...Les primeres tradicions funeráries coincideixen amb importants canvis en el patró diassentament [...]. La reiteració de l'ús d'un mateix indret funerari seria, doncs, una expressió, en sí mateixa, de l'ocupació permanent del territorio per part d'aquests grupos autoconscients". (VICENT, 1990).

+ Esto puede notarse claramente en el hábitat, donde se pasa de unos yacimientos de habitación en cuevas o abrigos característicos del mundo cardial a unos asentamientos al aire libre en zonas llanas. La ocupación del espacio difiere mucho de un momento a otro. 
Sin embargo, en una sociedad agrícola-ganadera, en la que no existe una especialización artesanal (excepto tal vez la propia fabricación de cuentas de variscita, pero que tiene lugar exclusivamente dentro de la explotación de las minas), ¿̨qué elemento podría tener tanta fuerza como para producir una marcada diferenciación social e incluso jerarquización? Ningún otro dato del registro arqueológico parece evidenciar esto (estructuras de habitación, etc.) y tradicionalmente siempre se piensa para este momento en un modo de producción comunal.

En uno de los artículos sobre la Bóbila Madurell se dice claramente que no existen muestras en el registro como para pensar en:

"la existencia de un grupo dominante que gestione el supuesto excedente correspondiente al trabajo productivo de los demás, lo cual implicaría una apropiación del mismo para su manutención y consolidación, así como el inicio de unas manifestaciones de poder, que no quedan aqui evidenciadas (ni en los enterramientos ni en el resto de las estructuras)" (Alaminos et alii, 1991).

Proponen entonces su propio modelo (Alaminos et alii, 1991; Blanch, 1991): una pequeña comunidad que generacionalmente ocuparía la misma zona y que basaría su

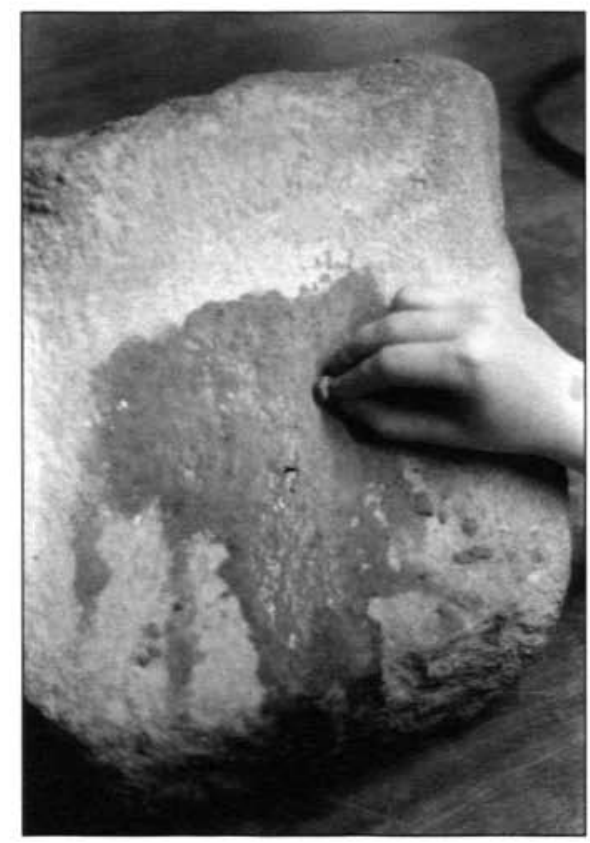

Lámina $\boldsymbol{V}$. Pulimento experimental de una cuenta. 


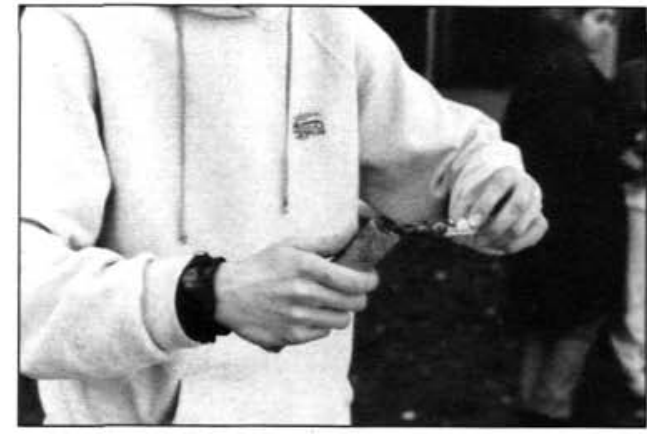

Lämina VI. Colscación de la almaciga sobre un palo de madera para sujetar posteriormente un fragmento de variscita para su pulimento.

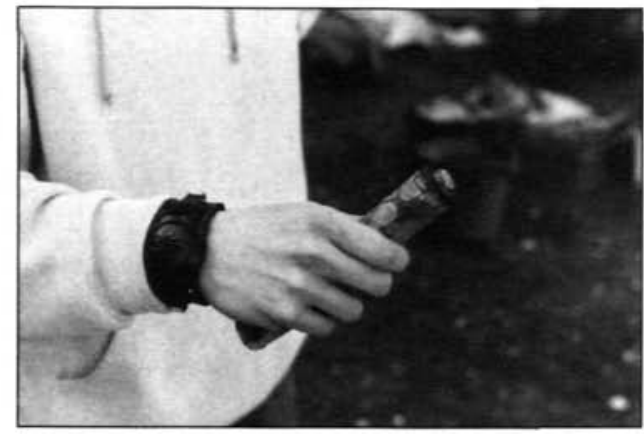

Lámina VII. Colocación de un fragmento de variscita sobre un palo de madera para su pulimento.

"poder adquisitivo" en la apropiación y distribución de la pequeña y variable plusvalía obtenida por las propias unidades familiares de explotación; el sistema productivo estaría destinado a cubrir las necesidades vitales y sociales a través de una producción intensa con una función doméstica, pero sin que ésta sea necesariamente autárquica, como demuestran ciertos materiales obtenidos forzosamente mediante el intercambio.

Esta hipótesis no respeta la idea tradicional de un modo de explotación comunal, pero se encuentra a mitad de camino entre la idea de una sociedad plenamente igualitaria (en la que no tienen cabida las diferencias de ajuar) y una sociedad plenamente jerarquizada (que no parece evidenciarse en el resto del registro material y que sería algo anacrónica para el periodo que nos ocupa).

Volviendo a las Minas, éstas presentan aparentemente una enorme complejidad en lo que respecta a su realización y explotación, que una vez examinada atentamente y diluyendo esa inversión de trabajo en el tiempo, podría ser mucho más sencilla de lo que pueda parecer. No sabemos, en realidad, cuánta gente trabajaría en las Minas en un mismo momento cronológico y desconocemos, por tanto, la magnitud de la explotación. Cuentan también con algunos elementos excepcionales que llaman la atención como es el caso de la Venus de Gavà, sin paralelos contemporáneos en la Península Ibérica, ya que las decoraciones oculadas de algunas cerámicas andaluzas o los "idolillos" murcianos (Ayala, en prensa) no parecen tener mucho que ver. Ha sido interpretada como una deidad asociada a cultos de fertilidad de la tierra (tanto a nivel agrícola como a nivel minero) vinculada a la figura de la diosa madre, presente en muchos yacimientos europeos contemporáneos (Bosch y Estrada, 1994).

La explotación de las Minas en busca de una materia prima dedicada exclusivamente a la fabricación de ornamentos es lo que las diferencia de otras minas europeas contemporáneas, otorgándoles un carácter especial. El adorno personal puede ser un sistema de información de las relaciones sociales. Por tanto, su abundancia implicaría la crisis de un orden social, que necesita verse reforzada a través de una serie de objetos simbólicos, que representarian la emergencia de nuevas relaciones sociales (VICENT, 1990). 
También Vicent, en este mismo artículo comenta que:

“... en algun moment del IV mil.leni l'esmentat procés sembla experimentar un punt d'inflexió, perceptible arqueològicament pel canvi d'escala de les esferes díntercanvi, la qual cosa facilita la presència creixent de materials de procedència distant, o escassos, o molt elaborats, o tot a la vegada. Els primers indicis d'una explotació sistemàtica $i$ massiva d'alguns d'aquest materials (per exemple, les mines de variscita de Can Tintoré, a Barcelona) abonen aquesta interpretació"(VICENT, 1990).

Con todas estas reflexiones, la polémica está servida.

El presente trabajo ha tratado, en primer lugar, acercarse a la tecnología de la fabricación de las cuentas de collar. Hemos podido reproducir con éxito todo el proceso, y las conclusiones extraídas de la experimentación, muy interesantes, han ido siendo expuestas en sus respectivos apartados. El verdadero reto aparece al tratar de obtener conclusiones de otro tipo de los resultados de la experimentación.

Antes de pasar a este aspecto, vamos a recordar brevemente los resultados de la experimentación:

\begin{tabular}{|l|c|c|}
\hline Tiempo medio de pulimento & 1 hora y 45 minutos $^{5}$ & 2 horas y 15 minutos $^{6}$ \\
\hline Tiempo medio de perforación & 1 hora y media & 1 hora y 45 minutos \\
\hline Tiempo medio del total del proceso de fabricación & 3 horas y 15 minutos & 4 horas \\
\hline Porcentaje de cuentas enteras tras el pulimento & \multicolumn{2}{|c|}{$68 \%$} \\
\hline Porcentaje de cuentas enteras tras la perforación & \multicolumn{2}{|c|}{$25 \%$} \\
\hline Porcentaje de cuentas enteras tras todo el proceso & \multicolumn{2}{|c|}{$25 \%$} \\
\hline
\end{tabular}

En principio, como ya mencioné en las conclusiones del apartado anterior, la manufactura de las cuentas se manifestó como un trabajo arduo y desagradecido, debido a la gran cantidad de tiempo y trabajo invertido sumado al esfuerzo de coordinar un grupo de trabajo, sobre todo de cara a que la recogida de datos fuera lo más exacta posible. Pero si analizamos los datos finales, las cifras de tiempo y medidas, y nos desprendemos del subjetivismo que implica la realización del trabajo como proceso de investigación en vez de como actividad artesanal, los resultados difieren bastante.

\footnotetext{
"Tiempos medios de las 11 cuentas terminadas.

${ }^{6}$ Tiempos medios de 10 cuentas (eliminando la cuenta $n^{2} 1$, con cifras muy alejadas del resto).
} 


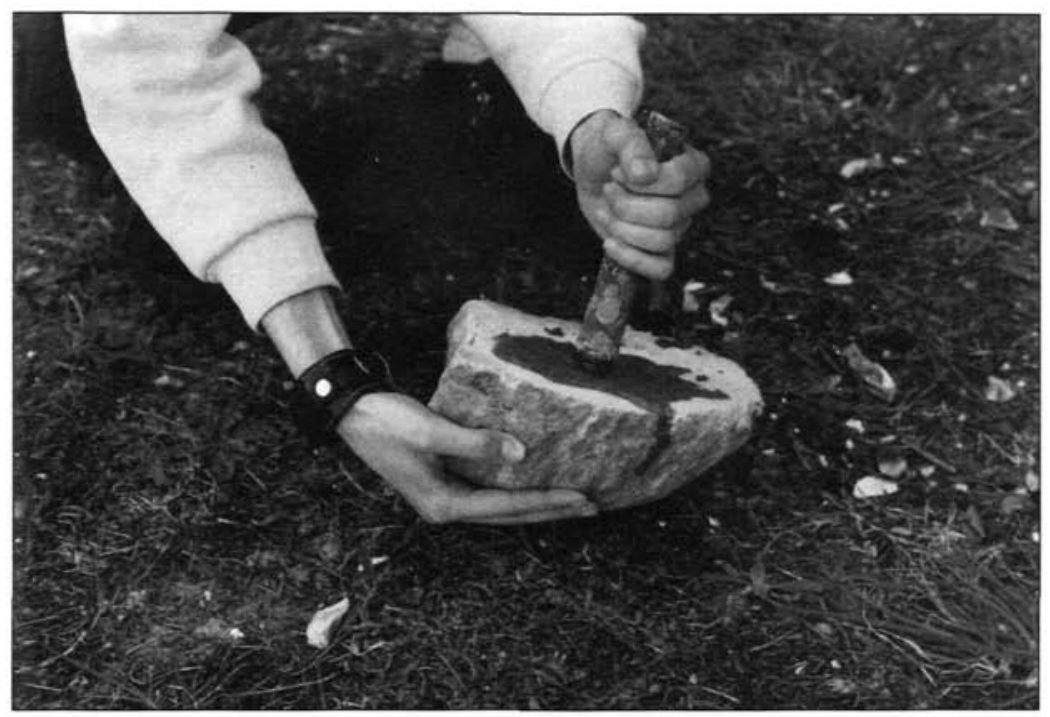

Lámina VIII. Pulimento de una cuenta de variscita con soporte de madera y arena y agua como abrasivo.

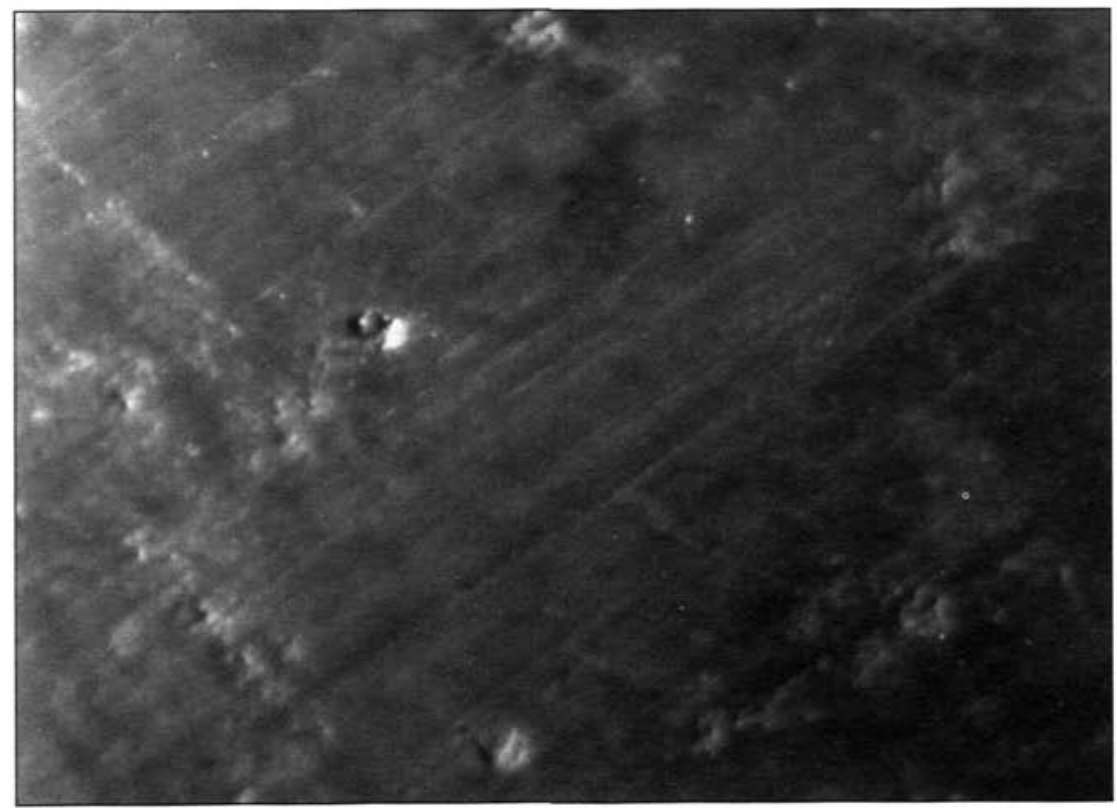

Lámina IX. Cuenta experimental. Estrías paralelas en la superficie 


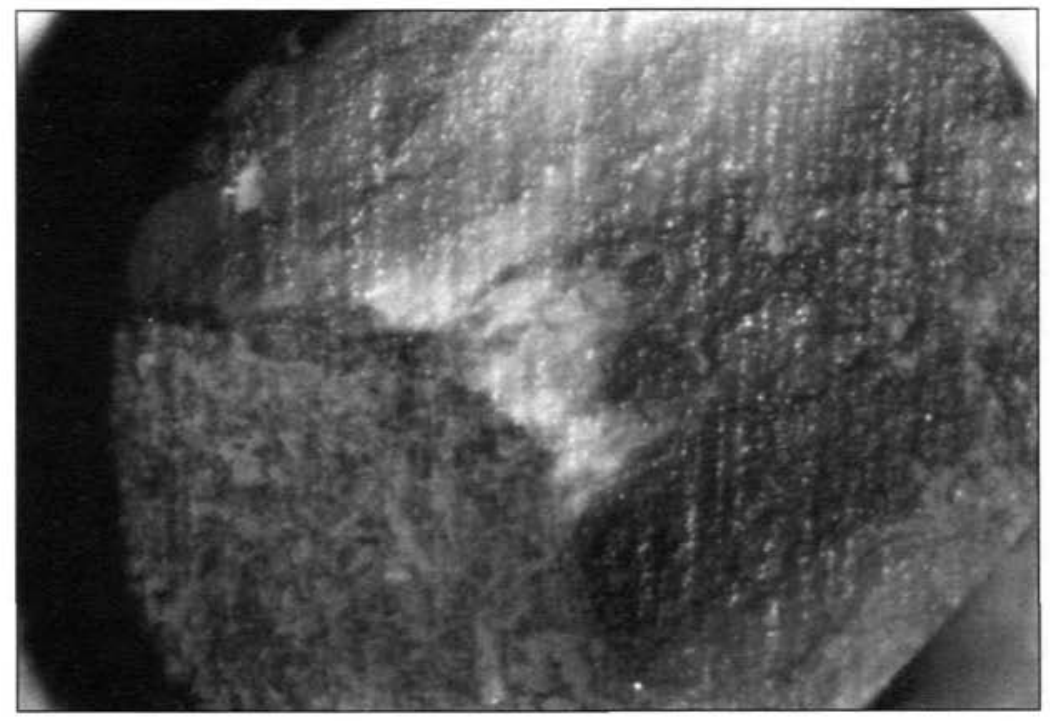

Lámina $\boldsymbol{X}$. Cuenta experimental. Estrias paralelas en la superficie.

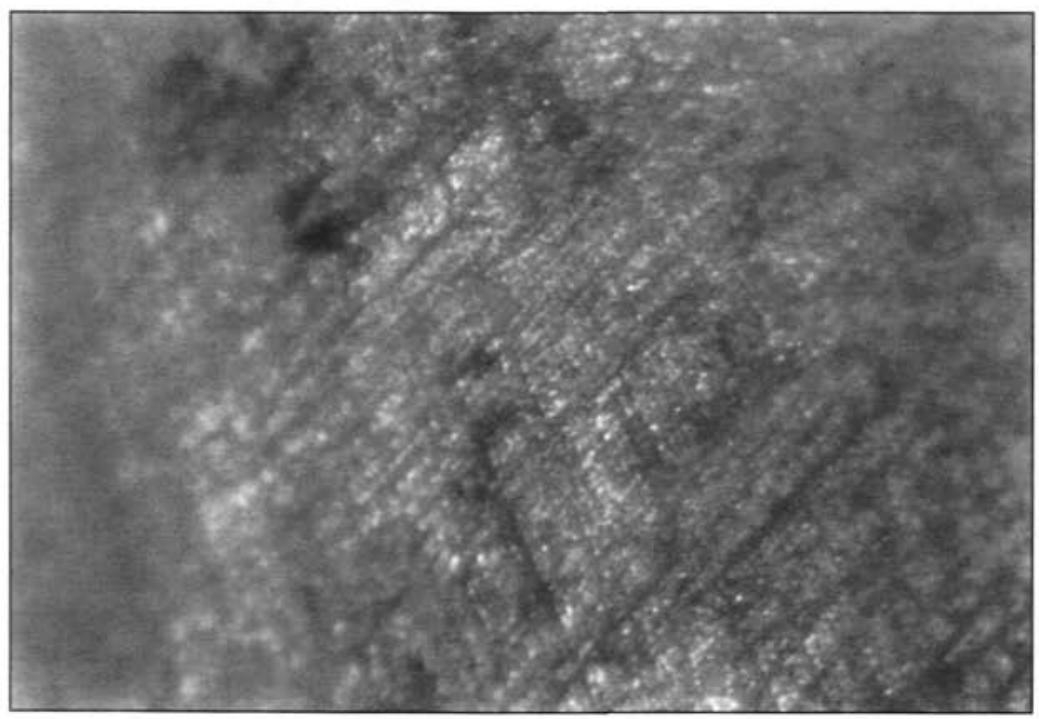

Lámina XI. Cuenta experimental. E-trias paralelas en la superficie superpuestas en dos direcciones distintas. 
Es cierto que la variscita es una materia prima difícil de trabajar, pero la realización de las cuentas es más una cuestión de inversión de tiempo, conocimiento exhaustivo de las materias primas, paciencia y habilidad personal que de dificultad tecnológica? ${ }^{7}$

Es posible que la fabricación de los instrumentos de trabajo (taladros y brocas) quedara en manos de trabajadores especializados pudiendo tratarse de los mismos talladores que se dedicaran a la fabricación del utillaje lítico empleado para otras tareas, pero la realización de las cuentas podía ser llevada a cabo por cualquier persona, sin ninguna cualificación especial, eso sí, con mayor o menor éxito, dependiendo de la habilidad de ésta. Para realizar una aleación de cobre y estaño y fabricar un hacha de molde hacen falta unos conocimientos técnicos muy concretos y especializados; para pulir y perforar una cuenta de variscita, no. Con esto no negamos la existencia de especialistas, sólo decimos que los artesanos no tenían porqué tener este carácter.

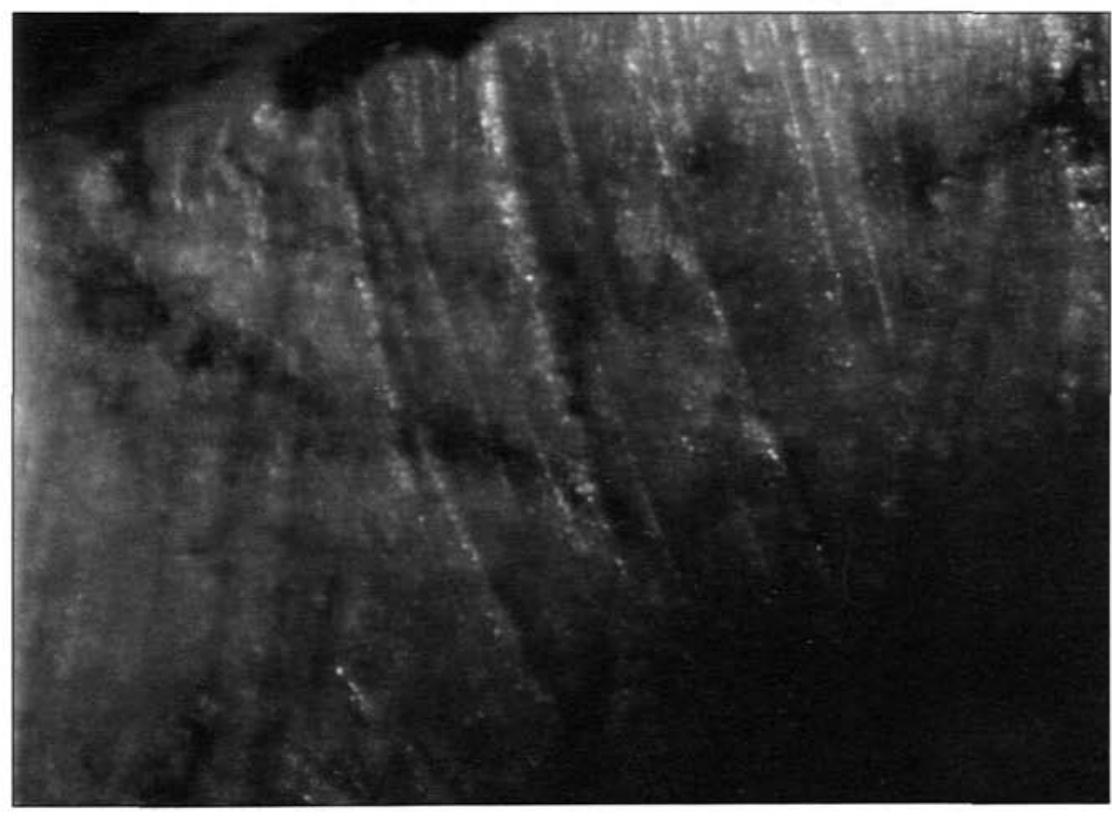

Lámina XII. Cuenta experimental. Estrias paralelas en la superficie superpuestas en dos direcciones distintas.

- Queremos de todas formas, insistir aquí que todos estos comentarios hacen referencia exclusivamente a las cuentas de collar discoidales. No sabemos si estas reflexiones podrian aplicarse de igual manera a las cuentas cilíndricas o de tonelete, aparentemente más complejas de fabricar, ya que, como es sabido, éstas no fueron incluidas en la experimentación. 


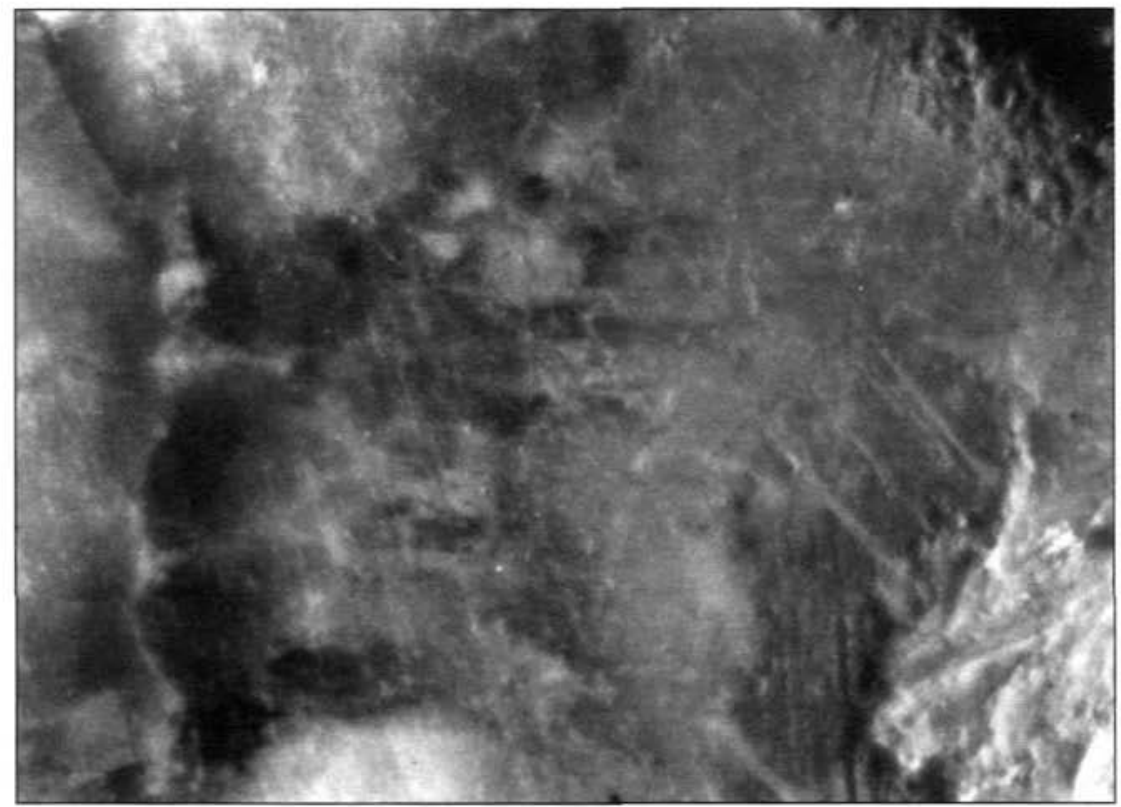

Lámina XIII. Cuenta experimental. Estrias paralelas en la superficie superpuestas en todas las direcciones anárquicamente.

Esto, en principio, nos haría mostrarnos en desacuerdo con la propuesta del primer equipo, según la cual:

“...dentro de este contingente especializado en el trabajo minero se incluye un subgrupo, igualmente especializado en la manufactura de las cuentas de collar fabricada a partir del mineral extraido" (Blasco, Edo y Villalba, 1996).

Parece evidente que la variscita tenía un valor especial, ya fuera por su color, su textura o motivos que pueden quedar absolutamente fuera de nuestro alcance. También parece clara su vinculación a un grupo cultural en concreto, tal vez incluso como signo diferenciador de otros grupos. Pero el resto de cuestiones que nos podemos formular han de quedar de momento en el aire: si la variscita era un elemento de prestigio, un diferenciador social y/o económico entre los miembros del grupo, un elemento simbólico que representaba cierto estatus o que tenía un simbolismo especial relacionado con la muerte, etc. En cualquiera de estos casos habría que plantearse cómo se desarrollaba su adquisición: si se trataba de una mera cuestión económica en la que se intercambiaba por otros productos (en este caso la posesión de cuentas correspondería a un mayor nivel de "riqueza") o intervenían otros factores como el prestigio social de una persona por sus cualidades. En ambos casos el estatus del propietario de las cuentas podría transmitirse a su familia (enterramientos infantiles). De momento, el resto del registro arqueológico no permite decantarse por ninguna de las opciones y sólo nos cabe esperar a que el conjunto de las investigaciones siga adelante. 


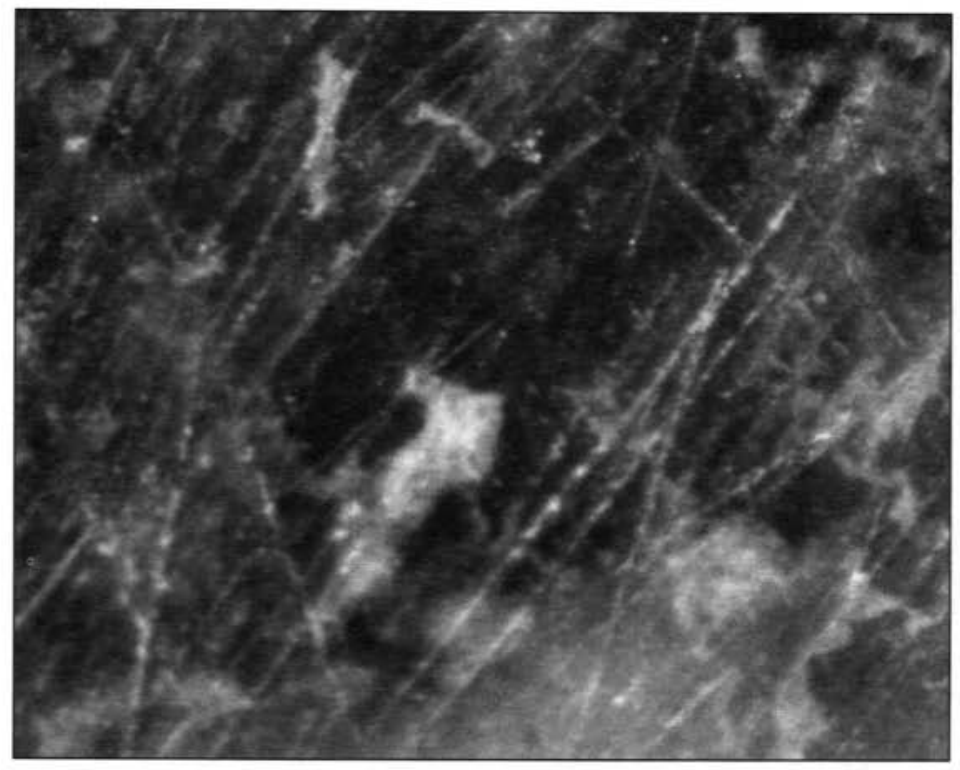

Lamina XIV. Cuenta experimental. Estrias paralelas en la superficie superpuestas en todas las direcciones anárquicamente.

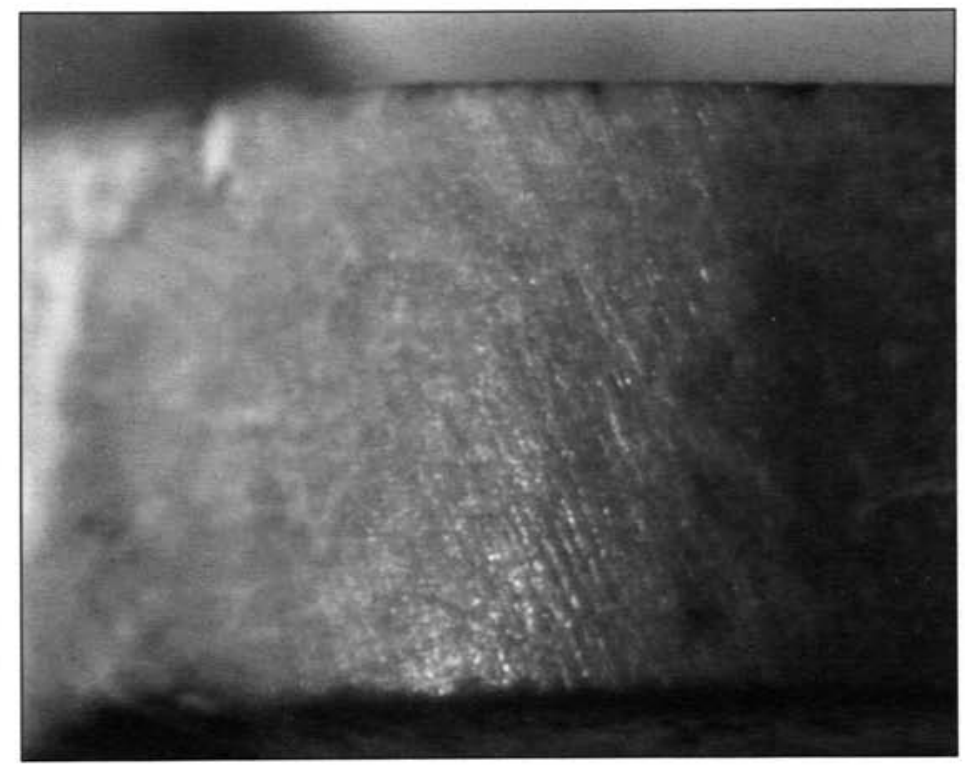

Lamina $\boldsymbol{X V}$. Cuenta experimental. Estrias oblicuas en el borde de la cuenta. 


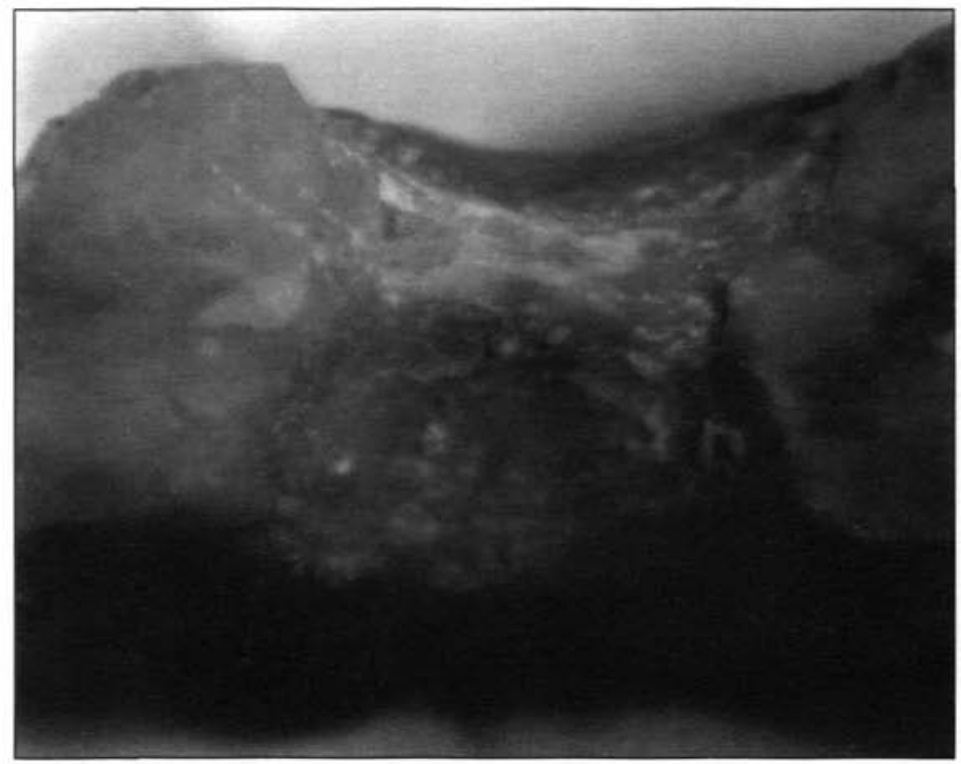

Lamina XVI. Cuent: experimental. Perforación en sección en forma de U.

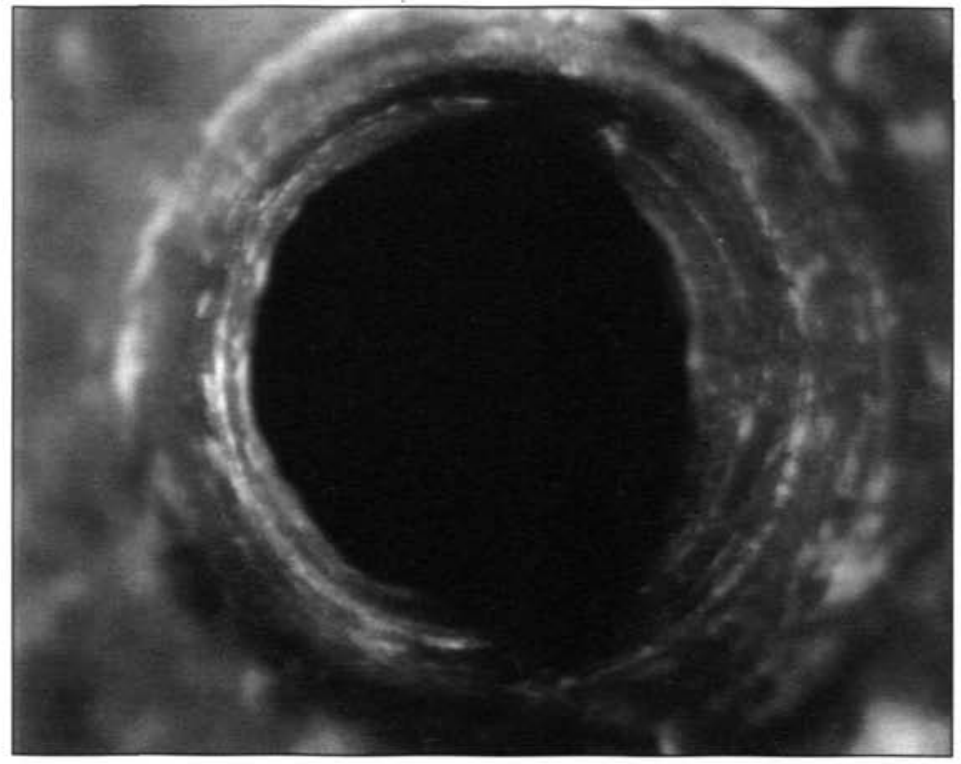

Lamina XVII. Cuenta experimental. Estrias circulares concéntricas en torno a la perforación. 


\section{BIBLIOGRAFÍA}

Alaminos, A.; Blanch, R.M. y Lazaro, P. (1991): "Bóbila Madurell. Su contribución al Neolítico Medio en Cataluña”. Revista de Arqueología, $n^{\circ}$ 128. Pág. 14-23.

AleKSHIN, V.A. (1983): "Burial Customs as an Archaeological Source". urrent Anthropology. Vol. 24, nº 2. Pág. 137-145.

Alonso, M.; Edo, M.; Gordo, L.; MIlan, M. y Villalba, M.J. (1977-78): "Explotación minera neolítica en Can Tintorer (Gavà, Barcelona)”. Pyrenae, n² 13-14. Pág. 7-20.

ARENAS, J. y BAÑolas, L. (1989): "Els perforadors de denes de variscita a Can Tintorer, una nova tipologia. Estudi experimental". I Jornades Arqueològiques del Baix Llobregat. Vol. I. Comunicacions. Pre Actes. Pág. 54-54.

ARENAS, J.; BAÑolas, L. y EDO, M. (1991): "La cal.laïta. transformació de la matèria primera a Can Tintorer". 9 $9^{\circ}$ Colloqui Internacional d'Arqueologia de Puigcerdà. Estat de la investigació sobre el Neolític a Catalunya. Pág. 200-202.

BIRKET-SMITH, K. (1959): The eskimos. Londres.

Blanch, R.M. (1991): "Restes d'ocupació: l'exponent de la Bòbila Madurell". 9 Colloqui Internacional d'Arqueologia de Puigcerdà. Estat de la investigació sobre el Neolític a Catalunya. Pág. 179-180.

Blasco, A.; Edo, M. y Villalba, M.J. (1990): "Les perles en Callaïs du Sud de la France proviennent-elles des Mines de Can Tintorer?". Colloque International Hommage au Dr. Jean Arnal. Le Chalcolitique en Languedoc. Ses relations extra-regionales. Pág. 279289.

- (1996): "Intercambio de bienes de prestigio. Catalunya durante el Neolítico. El desarrollo de la desigualdad social". Actas del I Congrés del Neolític a la Península Ibérica. Rubricatum, $\mathrm{n}^{\circ} 1$.

Bosch, J.; Carrete, J.; Estrada, A. y Verdaguer, T. (1993): "El Neolític antic evolucionat a les Mines Prehistóriques de Gavà: Noves aportacions del Projecte Mines Prehistòriques". Pyrenae, $\mathrm{n}^{2}$ 24. Pág. 57-77.

Bosch, J. y Estrada, A. (1994): "El Neolític Postcardial a les Mines Prehistòriques de Gavà (Baix Llobregat)". Rubricatum, $\mathrm{n}^{\circ} 0$.

- (1995): "Perspectivas y primeros resultados del Proyecto Minas Prehistóricas de Gavà (Barcelona)". Actas VI del I Congresso de Arqueologia Peninsular. Trabalhos de Antropología e etnología. Vol. 35 (2). Pág. 73-95.

- (1996): "La minería en Gavà (Bajo Llobregat) durante el IV milenio a.C." Actas del I Congrés del Neolític a la Península Ibérica. Rubricatum, n² 1. Pág. 265-270.

Bosch, J.; Estrada, A. Y Noain, M.J. (1996): "Minería Neolítica en Gavà (Baix Llobregat, Barcelona)". Trabajos de Prebistoria, junio de 1996. 
Casanova, V. (1978): "El enterramiento doble de la Cova de la Sarsa (Bocairente, Valencia)". Archivo de Prebistoria Levantina, XV, Valencia. Pág. 27-36.

Chantret, F.; Guilaine, J. y Guillemaut, A. (1970): "Les perles en callaïs. Analyses de specimens du Midi de la France". Pyrenae, n² 6. Pág. 29-37.

EDo, M. (1991): "La cal.laita a les terres de L'Ebre". XXVII Assamblea Intercomarcal d'eEstudiosos de Amposta.

EDo, M.; Blasco, A.; y Villalba, M.J. (1990): "Approche de la carte de distribution de la variscite des Mines de Can Tintorer, Gavà (Catalogne)". Cabiers du Quaternaire, $n^{2} 17$. Le silex de sa genèse à l'outil. Actes du $V^{Q}$ Colloque international sur le Silex. Pág. 287298.

- (1991): "Can Tintorer. Procedència i distribució de la cal.laïta catalana". 9 Colloqui Internacional d'Arqueologia de Puigcerdà. Estat de la investigació sobre el Neolític a Catalunya. Pág. 203-205.

- (1992): "Can Tintorer, origen y distribución de minerales verdes en el noreste peninsular durante el Neolítico". Aragón/Litoral mediterráneo. Intercambios culturales durante la Prebistoria. Homenaje a Maluquer de Motes. Institución Fernando el Católico, Zaragoza. Paág. 361-373.

- (1995): "La calaíta en al Península Ibérica". Actas VI del I Congresso de Arqueologia Peninsular. Trabalhos de Antropología e etnología. Vol. 35 (2). Pág. 127-167.

Fernández, A. y Pérez, E. (1988): "Los objetos de adorno en piedras verdes de la Península Ibérica”. Espacio, tiempo y forma. Serie I, Prehistoria, T. I. Pág. 239-252.

Gimeno, D.; Fernández, J.L.; Villalba, M.J.; Edo, M. y Blasco, A. (1996): "Complejo minero de Can Tintorer, Gavà: Geología y técnicas de explotación en el IV milenio”. Actas del I Congrés del Neolític a la Península Ibèrica. Pág. 259-263.

GODELIER, M. (1974): Economía, fetichismo y religión en las sociedades primitivas. Editorial s. XXI, Madrid.

Gómfz, P. (1992): "La dimensión social del adorno en las sociedades de cazadores-recoletores". Revista de Arqueología, $\mathrm{n}^{2} 138$.

HARRIS, M. (1980): Vacas, cerdos, guerras y brujas. Alianza Editorial, Madrid.

López, P. (coord.) (1988): El Neolítico en España. Ed. Cátedra, Madrid.

Llongueras, M. (1980): "La Cultura dels Sepulcres de Fossa del Neolític Mig-recent de Catalunya". El Neolític a Catalunya. Taula Rodona de Montserrat. Pág. 21-171.

Malinowski. B. (1975): Argonautas del Pacífico Occidental. Un estudio sobre comercio y aventura entre los indígenas de los archipiélagos de la Nueva Guinea Melanésica. Ed. Península, Barcelona.

Meneses, M.D. (1994): "Utiles de hueso del Neolítico Final del sur de la Península Ibérica empleados en alfarería: placas curvas, biseles, placas y apuntados". Trabajos de Prebistoria, 51, $\mathrm{n}^{\circ}$ 1. Pág. 143-156.

MerCADAl, O. Y Vives, E. (1991): “Noves dades sobre el ritual d'enterrament al neolític Mitjà: l'exemple de la Bòbila Madurell". 9 Colloqui Internacional díArqueologia de Puigcerdà. Estat de la investigació sobre el Neolític a Catalunya. Pág. 185-186. 
MuÑoz, A.M. (1965): La cultura neolítica catalana de los Sepulcros de Fosa. Barcelona.

NoAIn, M.J. (1996a): La Necrópolis de la Bòbila Madurell: un intento de análisis desde la arqueología de la muerte. Inédito.

- (1996b): "El adorno personal del Neolítico peninsular. Sus contenidos simbólicos y económicos”. Actas del I Congrés del Neolític a la Península Ibèrica. Pág. 271-278.

- (1997): "El proceso de fabricación de las cuentas de collar en variscita". Boletín de Arqueología Experimental, n²1. Pág. 10-11.

- (1998): Las cuentas en collar de variscita de las Minas Prebistóricas de Gavà (Minas de Can Tintorer). Bases para un estudio experimental. Memoria de Licenciatura.

PIEL-DesRuisseaux, J.L. (1989): Instrumental prehistórico. Forma, fabricación, utilización. Ed. Masson. Barcelona.

RIPOlL, E. y Llongueras, M. (1963): "La cultura neolítica de los sepulcros de fosa en Cataluña". Ampurias, $\mathrm{n}^{\circ} \mathrm{XXV}$. Paág. 1-85.

- (1967): "Notas sobre los Sepulcros de Fosa catalanes”. Ampurias n XXX. Pág. 240-257.

Rojo, M.A.; Delibes De CAStro, G.; Edo, M. y Fernádez, J.L. (1996): “Adornos de calaíta en los ajuares dolménicos de la provincia de Burgos: apuntes sobre su composición y procedencia”. Actas del I Congrés del Neolític a la Península Ibèrica. Pág. 239-247.

Rubio, I. (1989): El Neolítico Peninsular. Una interpretación de los datos arqueológicos. CuPAUAM, $\mathrm{n}^{2} 16$.

- (1993): "La función social del adorno personal en el Neolítico de la Península Ibérica". CUPAUAM, n² 20. Pág. 27-58.

SEMENOV, S.A. (1981): Tecnología prebistórica. Ed. Akal. Madrid.

SERVICE, R.E. (1962): Primitive social organization. An evolutionary perspective. Random House, Nueva York.

SAHLINS, M. (1983): Economía de la edad de piedra. Ed. Akal, Madrid.

SHERr, L. (1995): The history of beads. From 30.000 B. C. To the present. Ed. Abrams, Nueva York.

TABORIN, Y. (1993): La parure en coquillage au Paleolithique. C.N.R.S. Editions. París.

Ten CARne, R. (1977): “Un nuevo tipo de cuenta-colgante en el Neolítico catalán”. C.N.A., XV. Pág. 135-144.

V.V.A.A. (1991): Les joies de la Prehistòria. Generalitat de Catalunya. Barcelona.

VICENT, J.M. (1990): "El Neolític: transformacions socials y economiques". El canvi cultural a la Prehistoria (Anfruns y Llobet eds.). Ed. Columna, Barcelona. Pag. 241-293.

VILASECA, S. (1971-72): "A propósito de la calaíta o variscita”. AMPURIAS, n² 33-34. Pag. 287288.

Villalba, M.J.; Bañolas, L. y ARENAS, J. (1990): “Can Tintorer, Gavà (Catalunya). Une exploitation néolithique de phosphates et silicates". Cabiers du Quaternaire, $n^{2} 17$. Le silex de sa genèse à líoutil. Actes du $V^{o}$ Colloque international sur le Silex. Pág. 275-285.

Villalba, M.J.; Bañolas, L.; Arenas, J. y Alonso, M. (1986): Les mines neolitiques de Can Tintorer: Gavà. Excavacions 1.978-1.980. Generalitat de Catalunya, Barcelona. 
Villalba, M.J.; Blasco, A.; Edo, M: Arenas, J.A. y Bañolas, L. (1989): "Minería neolítica. Can Tintorer: una aportación fundamental". Revista de Arqueología, $\mathrm{n}^{2} 96$.

Villalba, M.J. Y EDO, M. (1991): “Aspectes sobre la mineria subterrània i la tecnologia apliada als sistemes díexploració". $9^{\circ}$ Colloqui Internacional d'Arqueologia de Puigcerdà. Estat de la investigació sobre el Neolític a Catalunya. Pág. 195-198.

Villalba, M. J.; Edo, M. y Blasco, A. (1989): "Zone d'influence de la callaïs de Can Tintorer". Identité du Chasséen. Actes du Colloque International de Nemours. Mémoires du Musée de Prehistoire dillle-de-France, $\mathrm{n}^{\mathrm{Q}}$ 4. Pág. 281-287.

- (1995): "Tecnología minera neolítica a partir del yacimiento de Can Tintorer (Gavà, Baix Llobregat)". Actas VI del I Congresso de Arqueologia Peninsular. Trabalhos de Antropologia e etnologia. Vol. 35 (2). Pag. 95-126.

VIVEs, E. (1980): "Les restes humanes en el Neolític a Catalunya". El Neolític a Catalunya. Taula rodona de Montserrat. Paág.227-231.

YERKES, R. W. (1993): "Methods of manufacturing shell beads at prehistoric Mississippian sites in southeastern North America". Traces et fonction: les gestes retrouvés. Colloque international de Liège. Editions Eraul, vol. 50. Pág. 235-242. 